\title{
Experimental and modeling study on the high-temperature oxidation of Ammonia and related NOx chemistry
}

\author{
Olivier Mathieu and Eric L. Petersen \\ Department of Mechanical Engineering, Texas A\&M University, College Station, TX 77843, USA
}

\begin{abstract}
Article Type: Full Length Article
Corresponding author:

Olivier Mathieu (olivier.mathieu@,tamu.edu)

Department of Mechanical Engineering, Texas A\&M University, College Station, TX 77843, USA

Tel: (+1) 9798457429
\end{abstract}

\begin{abstract}
:
Ammonia oxidation and ignition delay time measurements for pressures above $10 \mathrm{~atm}$ are scarce. In addition, $\mathrm{NH}_{3}$ is known to adsorb on stainless steel, so measurement results could be in question if wall passivation is not employed for apparatuses utilizing steel. To overcome these measurement difficulties and overall lack of high-pressure data for ammonia, new and methodical ignition delay time measurements have been performed behind reflected shock waves over a wide range of temperatures $(1560-2455 \mathrm{~K})$, pressures (around 1.4, 11, and $30 \mathrm{~atm})$ and equivalence ratios $(0.5,1.0$, and 2.0) for mixtures of ammonia highly diluted in $\operatorname{Ar}(98-99 \%)$. The new set of data from the present study was compared to several models from the literature. It was found that a large majority of the models do not predict the ignition delay times with accuracy, and there is a surprisingly wide variation amongst the predictions. One satisfactory model, from Dagaut and coworkers (2008), was selected and extended to compounds other than $\mathrm{NH}_{3}$ using $\mathrm{H}_{2} / \mathrm{O}_{2} / \mathrm{CO}, \mathrm{N}_{2} \mathrm{O}, \mathrm{NO}_{2}$, and $\mathrm{NNH}$ sub-mechanisms from the literature. The resulting comprehensive mechanism predicts well the ammonia ignition delay time data from the present study along with other $\mathrm{NH}_{3}, \mathrm{NO}_{2}$, and $\mathrm{N}_{2} \mathrm{O}$ data from the authors as well as from the literature with high accuracy. In addition to the new ammonia oxidation data and related model comparisons, the present paper documents a state-of-the-art NOx sub-mechanism that can be used for a wide range of combustion calculations when added to, for example, baseline mechanisms involving hydrogen and hydrocarbon kinetics.
\end{abstract}

Keywords: ammonia, ignition delay time, shock tube, high pressure, detailed kinetics modeling

\section{Introduction}

Ammonia $\left(\mathrm{NH}_{3}\right)$ is an impurity commonly found in gaseous fuels derived from the gasification processes of biomass [1] or coal [2] and is one of the largest sources of nitrogen leading to NO formation during coal combustion [3]. Depending on the conditions under which coal or biomass volatile matter is burned, the ammonia can either be converted to $\mathrm{NO}$ (fuel-NOx (oxides of nitrogen) formation mechanism) or to $\mathrm{N}_{2}$ [3-6]. Ammonia has also a key role in de-NOx processes [4], [7-10] and can also be used directly as a fuel in internal combustion engines [11-12] or as a hydrogen vector [12]. 
Since NOx emissions from industrial processes and energy production plants have been a concern for decades, a large body of research on $\mathrm{NH}_{3}$ oxidation - NOx formation/removal in flames [12-21], shock tubes [22-37] or flow reactors [3], [38-43] - is now available. In parallel with this large body of experimental studies, a great number of detailed combustion mechanisms containing ammonia submechanisms are currently available in the literature [5], [12], [44-50].

Despite this extensive number of studies, more work is still required to further validate the model over a wider range of conditions (as shown by some recent studies focusing on fuel rich - intermediate temperature [43] or oxy-combustion conditions [51]) or to clarify certain reaction pathways (such as the study on the role of $\mathrm{NNH}$ in $\mathrm{NO}$ formation and control using $\mathrm{NH}_{3}$ as a reducing agent by Klippenstein et al. [50]). For instance, it is worth mentioning that the pressure domain above 10 atm remains fairly unexplored with regard to $\mathrm{NH}_{3}$. In fact, to the best of the authors' knowledge, only the shock-tube study of Drummond [33], where ignition delay times were measured, has been performed above $10 \mathrm{~atm}$. However, this high-pressure set of data is provided for a broad yet unclear range of pressure, reported to be between 27.2 and 44.4 atm, which makes it difficult to use these data to validate a model. Shocktube ignition delay time measurements under well-defined conditions for pressures in excess of $10 \mathrm{~atm}$ are therefore necessary to further validate $\mathrm{NH}_{3}$ models at high pressure.

The modeling of ignition delay times $\left(\tau_{\text {ign }}\right)$ obtained in shock tubes is indeed a convenient way to assess the overall validity of a detailed kinetics mechanism at high temperatures and well defined conditions. However, when modeling shock-tube data from the literature, large discrepancies in the results can be observed amongst the aforementioned detailed mechanisms, as can be seen from Fig. 1, where data from Fuji et al. [34] are compared to several literature models. Differences of above one order of magnitude are observed between the mechanism from Dagaut et al. [48] and the mechanism of Mueller et al. [45].

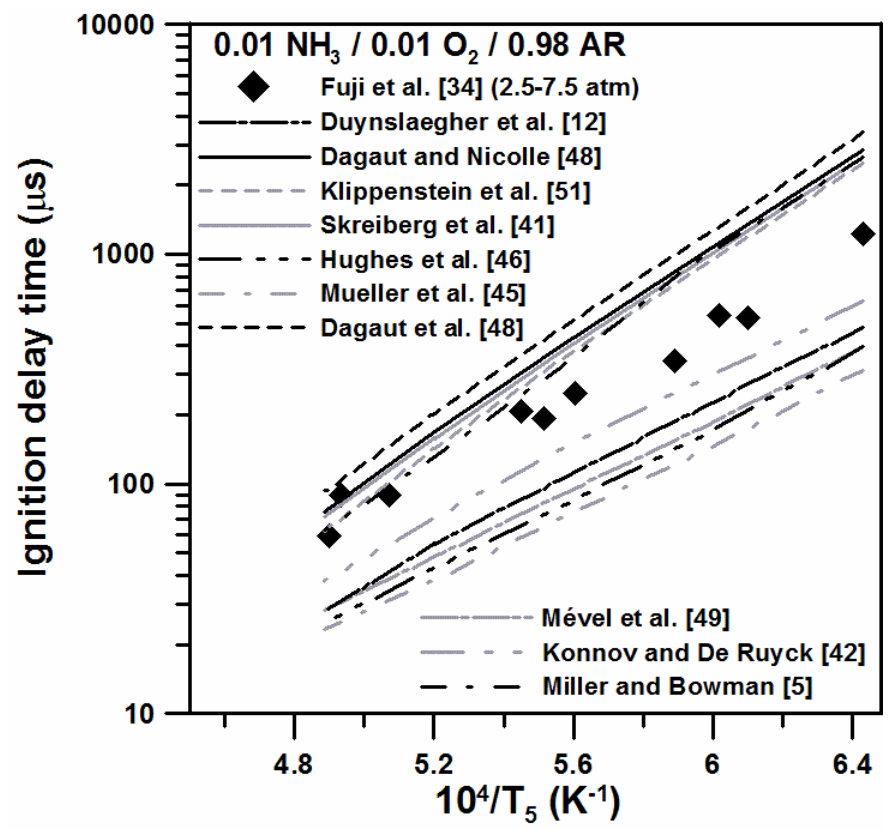

Figure 1: Comparison between experimental data from Fuji et al. [34] and available models from the literature. Experimental data are given for a pressure range between 2.5 and $7.5 \mathrm{~atm}$, and the modeling was performed at $5 \mathrm{~atm}$.

Nonetheless, it is visible in this figure that the mechanisms from the literature do not predict correctly the experimental data, especially on the lower-temperature side, and there are large differences 
amongst the various mechanisms. Literature kinetics models can be separated into two groups: underand over-reactive mechanisms. The best mechanism from the over-reactive group is the mechanism of Konnov and De Ruyck [42] with a factor around 2 between the experiments and the calculation. The other mechanisms from this group are either older [45] or are based on this mechanism [12, 49]. It is interesting to note that the group of the under-reactive mechanisms is composed of the more-recent mechanisms (if we exempt the mechanism from Miller and Bowman [5]). These mechanisms present good to acceptable predictions at high temperatures, above $1800 \mathrm{~K}$, but are not reactive enough, by a factor between two and three, below this temperature. However, a further analysis of the data shows that it would be difficult to fully assess the validity of these detailed kinetics models based on the data in Fig. 1 or with other ignition delay time data obtained in shock tubes from the literature. Unfortunately, most of the shock-tube studies from the literature do not report the pressure and/or temperature conditions with an acceptable level of precision. For example, the pressure in Fig. 1 was reported as 2.5$7.5 \mathrm{~atm}$ in Fuji et al. [34], so the modeling was therefore conducted at an intermediate pressure of $5 \mathrm{~atm}$. This difference in pressure can partly explain the disagreement observed between the models and the data. In addition, it is important to mention that ammonia adsorbs on stainless steel, a material typically used to build shock tubes. Hence, accurate measurements necessitate a passivation of the shock-tube surfaces before conducting the experiment $[4,7]$. Unfortunately, no shock-tube studies where ignition delay times are measured report such passivation of the reactor's walls. This lack of wall passivation means that mixtures from the literature could present concentrations in ammonia that are probably lower than what was actually reported in the papers, depending on the surface polishing and the material of the shock tube considered. This systematic uncertainty could lead to equivalence ratios that are smaller than those reported, particularly for diluted mixtures where the $\mathrm{NH}_{3}$ concentration is low, which constitutes most of the data available in the literature. One can therefore conclude that new shock-tube ignition delay time measurements with well-characterized and high-pressure conditions, with surface passivation, would be necessary to further develop and validate $\mathrm{NH}_{3}$ models.

The first objective of this study was therefore to measure ignition delay times for $\mathrm{NH}_{3}$ mixtures highly diluted (98-99\% Ar dilution) in a shock tube. Experiments were performed behind reflected shock waves, after surface passivation of the reactor walls, for pressures around 1.4, 11, and 30 atm and for equivalence ratios set to $0.5,1.0$, and 2.0. These data were then compared to the literature mechanisms. A detailed chemical kinetics model was then selected, and the second main objective of the present study was therefore to improve this mechanism to also predict correctly a wide range of $\mathrm{NH}_{3}$, $\mathrm{HCN}$, and $\mathrm{H}_{2} / \mathrm{NOx}$ data from the literature. Details on the experimental procedure are covered first, followed by the experimental results and the model's improvement and validation stages.

\section{Methods}

The single-diaphragm, stainless steel, shock tube used during this study has a driven section that is 15.24-cm i.d., 4.72-m long, and a driver section that is 7.62-cm i.d., 2.46-m long. Details and schematics of the shock-tube setup can be found in Aul et al. [52]. Five PCB P113A piezoelectric pressure transducers, equally spaced alongside the driven section and mounted flush with the inner surface were used along with four Fluke PM-6666 timer/counter boxes to measure the incident-wave velocities. A curve fit of these four velocities was then used to determine the incident wave speed at the endwall location. Post reflected-shock conditions were obtained using this extrapolated wave speed in conjunction with one-dimensional shock relations and the initial conditions at the test region. This method was proven to maintain the uncertainty in the temperature determination behind reflected shock waves $\left(T_{5}\right)$ below $10 \mathrm{~K}$ [53]. Test pressure was monitored by one PCB 134A transducer located at the endwall and one Kisler 603 B1 transducer located at the sidewall, in the same plane as the observation 
windows (Sapphire, located $16 \mathrm{~mm}$ from the endwall). Non-ideal boundary layer effects measured by the change in pressure $(\mathrm{dP} / \mathrm{dt})$ behind the reflected shock wave were determined to be less than $2 \%$ per ms for all experiments. The corresponding increase in temperature for these $\mathrm{dP} / \mathrm{dt}$ levels would be less than $10 \mathrm{~K}$ for the longest ignition delay times reported in this study and therefore does not have a noticeable impact on the results herein.

Experiments were performed at three different pressure conditions (around 1.4, 11, and $30 \mathrm{~atm}$ ), and three equivalence ratios $(\phi), 0.5,1.0$, and 2.0. Polycarbonate diaphragms were used for test pressures of 1.4 and $11 \mathrm{~atm}(0.25-\mathrm{mm}$ and $2 \times 1.02-\mathrm{mm}$ thickness, respectively), while pre-scored aluminum diaphragms (2.29-mm thickness) were used for the 30-atm experiments. When polycarbonate diaphragms were used, a cross-shaped cutter was employed to facilitate breakage of the diaphragm and prevent diaphragm fragments from tearing off. Helium was used as driver gas during this study.

The driven section was vacuumed down to $2 \times 10^{-5}$ Torr or better using a roughing pump and a Varian 551 Turbomolecular pump prior to every run. The pumping time between experiments was minimized using a pneumatically driven poppet valve matching the inside diameter of the driven section and allowing for a passage of 7.62-cm diameter between the vacuum section and the driven tube. The pressure was measured using two MKS Baratron model 626A capacitance manometers (0-10 Torr and 0-1000 Torr) and an ion gauge for high vacuums. Test mixtures were prepared manometrically in a mixing tank of 3.05-m length made from stainless steel tubing with a $15.24-\mathrm{cm}$ ID. The pressure in the mixing tanks was measured using a Setra GCT-225 pressure transducer (0-17 atm). The mixing tank is connected to the vacuum system and can be pumped down to pressures below $1 \times 10^{-6}$ Torr. The gases (Ammonia (Praxair, 99.9\% purity diluted in 94.92\% Ar (99.999\% purity)), $\mathrm{O}_{2}$ (Praxair, 99.999\% purity), and $\mathrm{Ar}$ (Acetylene Oxygen Company, $99.999 \%$ purity)) were passed through a perforated stinger traversing the center of the mixing tank to allow for rapid, turbulent mixing. To further ensure homogeneity through diffusion processes, mixtures were allowed to rest for at least 1 hour prior to making the first run. No difference in the results was observed for longer mixing times.

Since $\mathrm{NH}_{3}$ adsorbs on stainless steel [4], [54], the mixing tank and shock-tube surfaces were passivated with $\mathrm{NH}_{3}$ before the mixture preparation and before each experiment. The passivation method was as follows: introduction of around 100 torr of $\mathrm{NH}_{3}$ for at least 5 minutes in the vessel (i.e. mixing tank or shock tube) and then vacuuming for 5 minutes with the rough pump (until around 40 mtorr, typically) before filling with the mixture (shock tube) or mixture components (mixing tank). Mixtures and conditions investigated during this study are summarized in Table 1.

Table 1: Experimental conditions investigated behind reflected shock waves.

\begin{tabular}{|c|c|c|c|}
\hline Mixture composition (mole fraction) & $\begin{array}{c}\text { Equivalence } \\
\text { ratio }(\phi)\end{array}$ & $\mathrm{T}_{5}(\mathrm{~K})$ & $\mathrm{P}_{5}(\mathrm{~atm})$ \\
\hline $0.004 \mathrm{NH}_{3} / 0.006 \mathrm{O}_{2} / 0.99 \mathrm{Ar}$ & 0.5 & $\begin{array}{l}1925-2480 \\
1625-2015 \\
1560-1895 \\
\end{array}$ & $\begin{array}{l}1.4 \pm 0.1 \mathrm{~atm} \\
10.9 \pm 0.5 \mathrm{~atm} \\
28.7 \pm 1.0 \mathrm{~atm}\end{array}$ \\
\hline $0.005715 \mathrm{NH}_{3} / 0.004285 \mathrm{O}_{2} / 0.99 \mathrm{Ar}$ & 1.0 & $\begin{array}{l}1985-2490 \\
1660-2080 \\
1565-1930\end{array}$ & $\begin{array}{c}1.4 \pm 0.1 \mathrm{~atm} \\
10.8 \pm 0.4 \mathrm{~atm} \\
28.7 \pm 1.0 \mathrm{~atm}\end{array}$ \\
\hline $0.01143 \mathrm{NH}_{3} / 0.00857 \mathrm{O}_{2} / 0.98 \mathrm{Ar}$ & 1.0 & $\begin{array}{l}1825-2455 \\
1615-2085 \\
1565-1870 \\
\end{array}$ & $\begin{array}{l}1.4 \pm 0.1 \mathrm{~atm} \\
10.5 \pm 0.4 \mathrm{~atm} \\
28.6 \pm 0.6 \mathrm{~atm}\end{array}$ \\
\hline $0.007273 \mathrm{NH}_{3} / 0.002727 \mathrm{O}_{2} / 0.99 \mathrm{Ar}$ & 2.0 & $\begin{array}{l}1990-2360 \\
1650-2040 \\
1580-1910\end{array}$ & $\begin{array}{c}1.4 \pm 0.1 \mathrm{~atm} \\
10.6 \pm 0.6 \mathrm{~atm} \\
28.9 \pm 1.5 \mathrm{~atm}\end{array}$ \\
\hline
\end{tabular}


The ignition delay time was measured using the chemiluminescence emission from the $A^{2} \Sigma+\rightarrow X^{2} \Pi$ transition of the excited-state hydroxyl radical $\left(\mathrm{OH}^{*}\right)$ using an interference filter centered at $307 \pm 10$ nm with a Hamamatsu 1P21 photomultiplier tube in a custom-made housing. The ignition delay time is defined herein as the time between the passage of the reflected shock wave, indicated by a pressure jump in the signal delivered by the sidewall pressure transducer, and the intersection of lines drawn along the steepest rate-of-change of $\mathrm{OH}^{*}$ de-excitation and a horizontal line which defines the zeroconcentration level, as can be seen in Fig. 2. Time zero is defined as the time of arrival of the reflected shock wave at the sidewall measurement location. Note the typical $\mathrm{OH}^{*}$ profiles for $\mathrm{NH}_{3}$ at this pressure condition, where the $\mathrm{OH}^{*}$ signal does not come back to zero and stays flat for a few hundred microseconds (at least) after the ignition. All of the data signals were recorded through a 14-bit GageScope digital oscilloscope with sampling rates of $1 \mathrm{MHz}$ or greater per channel.

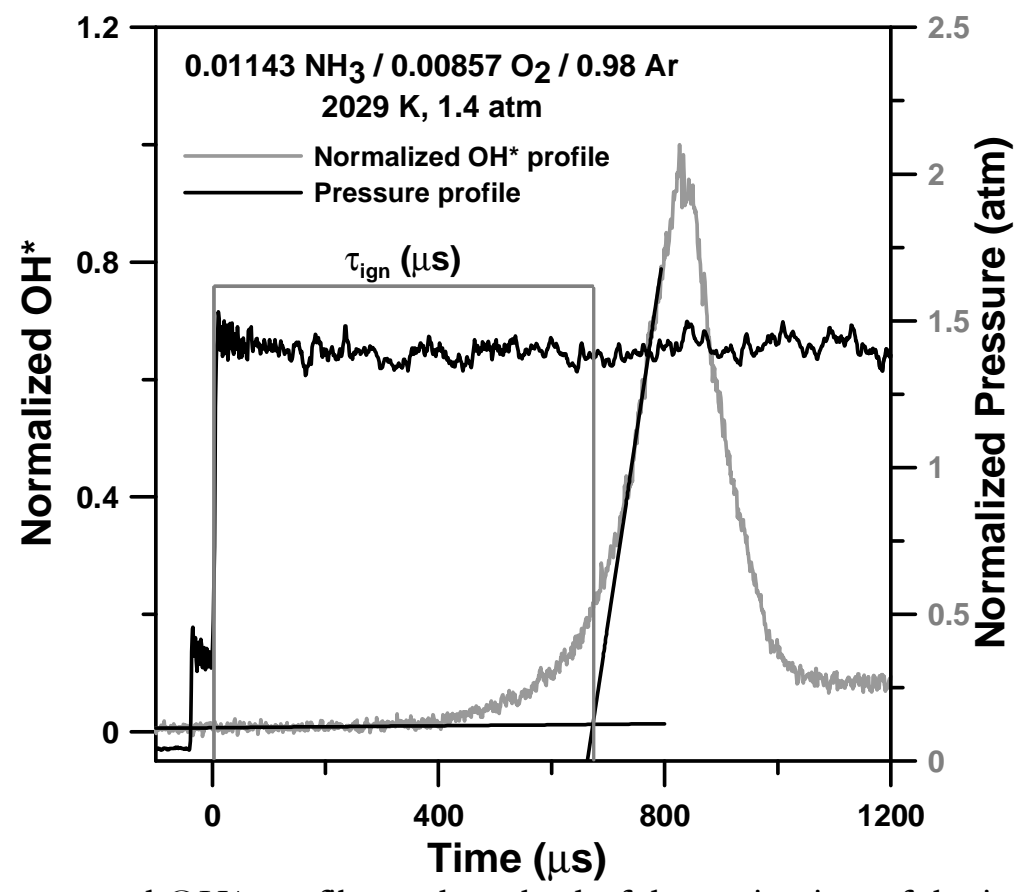

Figure 2: Typical pressure and $\mathrm{OH}^{*}$ profiles and method of determination of the ignition delay time.

There are essentially two sources of uncertainties in the ignition delay time: the uncertainty in the determination of the temperature behind the reflected shock wave $\left(T_{5}\right)$ and the uncertainty associated with the determination of the steepest rate of change from the $\mathrm{OH}^{*}$ profile. The temperature determination is the most important uncertainty and, as mentioned earlier, the experimental setup and method used allow for a determination of $\mathrm{T}_{5}$ within less than $10 \mathrm{~K}$. Thanks to the high signal/noise ratio of the experimental signals, the second source of uncertainty was small and can be neglected. Overall, the total uncertainty in $\tau_{\text {ign }}$ reported in this study is estimated to be $10 \%$ (which also includes the minimal temperature variation with facility $\mathrm{dP} / \mathrm{dt}$ ).

\section{Experimental Results}

\section{Equivalence ratio effect}


The equivalence ratio effects on the ignition delay times for ammonia are visible in Fig. 3 at pressures around $1.4 \mathrm{~atm}(3 \mathrm{a}), 11 \mathrm{~atm}(3 \mathrm{~b})$, and $30 \mathrm{~atm}(3 \mathrm{c})$. As can be seen, at pressures of $11 \mathrm{~atm}$ and above, the ignition delay times obtained at $\phi=1.0$ and 2.0 are very similar, while ignition delay times obtained at $\phi=0.5$ are shorter (by a factor around 1.5). At the lowest pressure investigated, around 1.4 atm (Fig. 3a), the equivalence ratio seems to have only a moderate effect on $\tau_{\text {ign }}$. However, at this lowerpressure condition, ignition delay times at the stoichiometric condition seem to be longer than for the other conditions (although ignition delay times at $\phi=0.5$ are similar for high temperatures). The activation energies (Ea) extracted from Fig. 3 show that Ea does not vary much with the equivalence ratio at $11 \mathrm{~atm}$ and above $(\mathrm{Ea}=39.5,40.1$, and $40.1 \mathrm{kcal} / \mathrm{mol}$ at $11 \mathrm{~atm}$ for $\phi=0.5,1.0$, and 2.0, respectively and $\mathrm{Ea}=42.5,42.0$, and $44.1 \mathrm{kcal} / \mathrm{mol}$ at $30 \mathrm{~atm}$ for $\phi=0.5,1.0$, and 2.0, respectively). However, it seems that Ea increases slightly with the equivalence ratio for the lowest pressure investigated: $\mathrm{Ea}=44.6,51.7$, and $56.3 \mathrm{kcal} / \mathrm{mol}$ for $\phi=0.5,1.0$, and 2.0, respectively, at $1.4 \mathrm{~atm}$. Note that this result could partly come from the small amount of curvature observed on the low-temperature side of the curve.

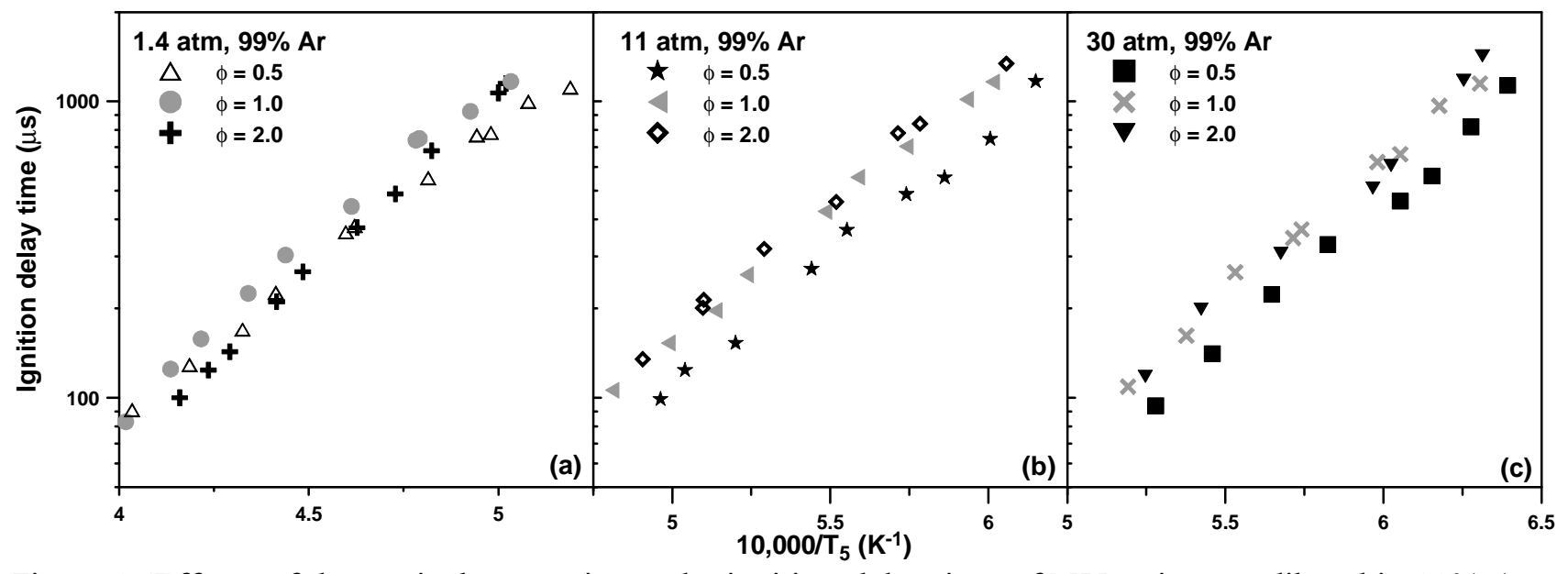

Figure 3: Effects of the equivalence ratio on the ignition delay time of $\mathrm{NH}_{3}$ mixtures diluted in $99 \% \mathrm{Ar}$ at around (a) $1.4 \mathrm{~atm}$, (b) $11 \mathrm{~atm}$, and (c) $30 \mathrm{~atm}$.

\section{Pressure effect}

As can be seen in Fig. 4 (a-d), there is an important effect of pressure on the ignition delay time of the ammonia-oxygen-argon mixtures, for all the equivalence ratios and levels of Ar dilution investigated. It is visible in this figure that the ignition delay time decreases with the increase in the pressure. A factor around 7 is found between ignition delay times obtained at 1.4 and $11 \mathrm{~atm}$ at $2000 \mathrm{~K}$ for all conditions investigated, while smaller factors of $1.8,1.9$, and 2.2 were found at $1700 \mathrm{~K}$ amongst $\tau_{\text {ign }}$ obtained at 11 and $30 \mathrm{~atm}$ for $\phi=0.5,1.0$ (at both dilution levels), and 2.0, respectively. 


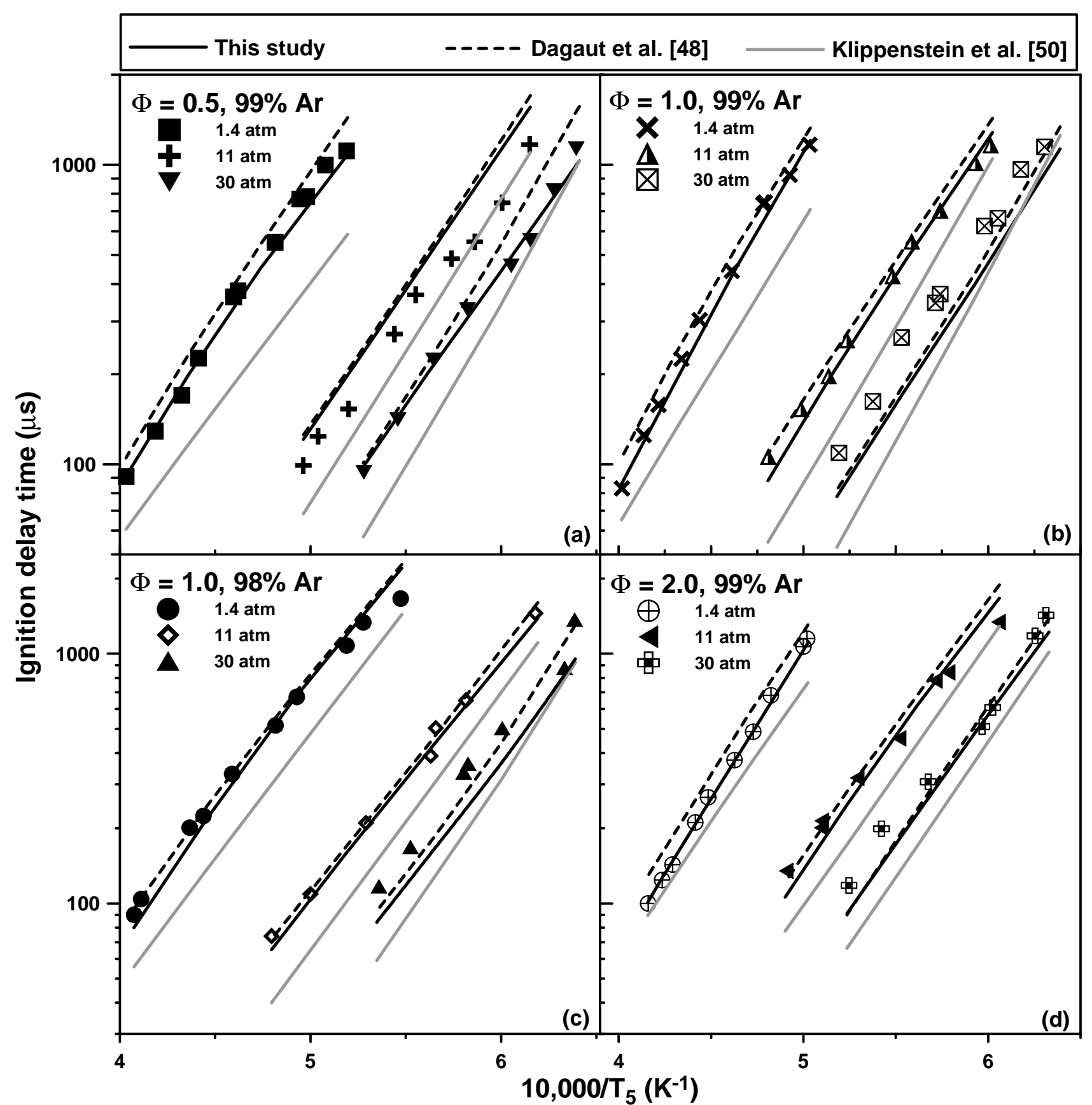

Figure 4: Effects of the pressure on the ignition delay time of $\mathrm{NH}_{3}$ mixtures at equivalence ratios of (a) 0.5, 1.0 (b) 99\% and (c) 98\% Ar dilution) and (d) 2.0. Lines correspond to modeling. Black line: this study, dashed line: Dagaut et al. [48], grey line: Klippenstein et al. [50].

\section{Fuel concentration effect}

By comparing the data obtained at $\phi=1.0$ for the $98 \%$ and $99 \%$ dilution in Ar cases, Fig. 5, one can see the effect of a factor 2 of the $\mathrm{NH}_{3}$ concentration on the ignition delay time. As can be seen in this figure, at around $1.4 \mathrm{~atm}$ (5a), ignition delay times are typically shorter for the $98 \%$ dilution case. However, the ignition delay times tend to converge toward a similar value as the temperature increases, $\tau_{\text {ign }}$ being similar for temperatures above 2270 K. For higher pressures, 11 atm (Fig. 5b) and 30 atm (Fig. 
5c), the ignition delay times are also shorter for the lowest dilution ratio, and also tend to converge toward a similar value at a given temperature. However, for these higher-pressure cases, ignition delay times converge toward the same value on the lower-temperature side. Activation energies for the mixtures with 98\% Ar dilution are 42.0, 43.0, and $46.7 \mathrm{kcal} / \mathrm{mol}$ at 1.4, 11, and $30 \mathrm{~atm}$, respectively. These values compare with the value obtained for the $99 \%$ Ar dilution, except for the low-pressure case where $\mathrm{Ea}$ is higher for the highest dilution level $(51.7 \mathrm{kcal} / \mathrm{mol})$.

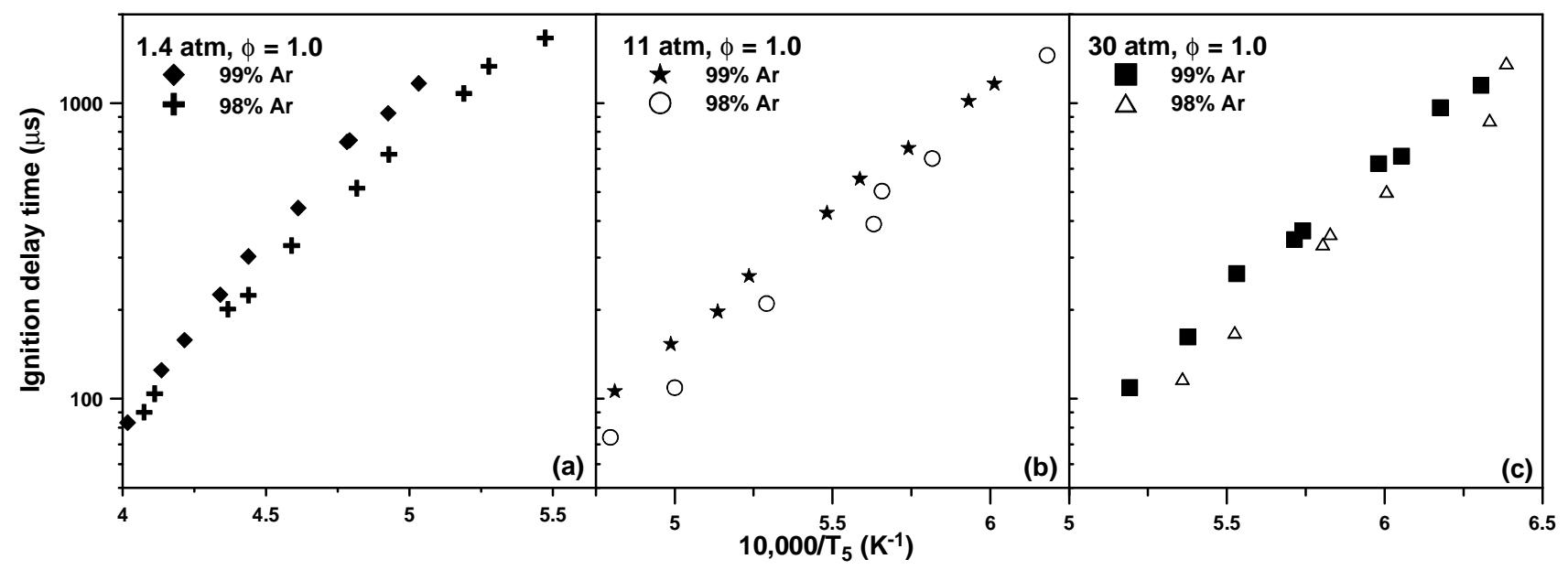

Figure 5: Effect of the dilution level (98 and 99\% Ar) on the ignition delay time of $\mathrm{NH}_{3}$ at around (a) 1.4 atm, (b) $11 \mathrm{~atm}$, and (c) $30 \mathrm{~atm}$ and at $\phi=1.0$.

Using the shock-tube data presented herein, it was possible to derive the following correlation $\left(\mathrm{r}^{2}=\right.$ 0.955), with $\mathrm{P}$ in atm and $\mathrm{T}_{5}$ in $\mathrm{K}$ :

$\tau_{i g n}(\mu s)=16.81 .10^{-3} \varphi^{0.18} P^{-0.89} \exp \left(44.11(k C a l) / R T_{5}\right)$

The comparison between the ignition delay times value measured experimentally and determined with the correlation R1 is visible in Fig. 6. 


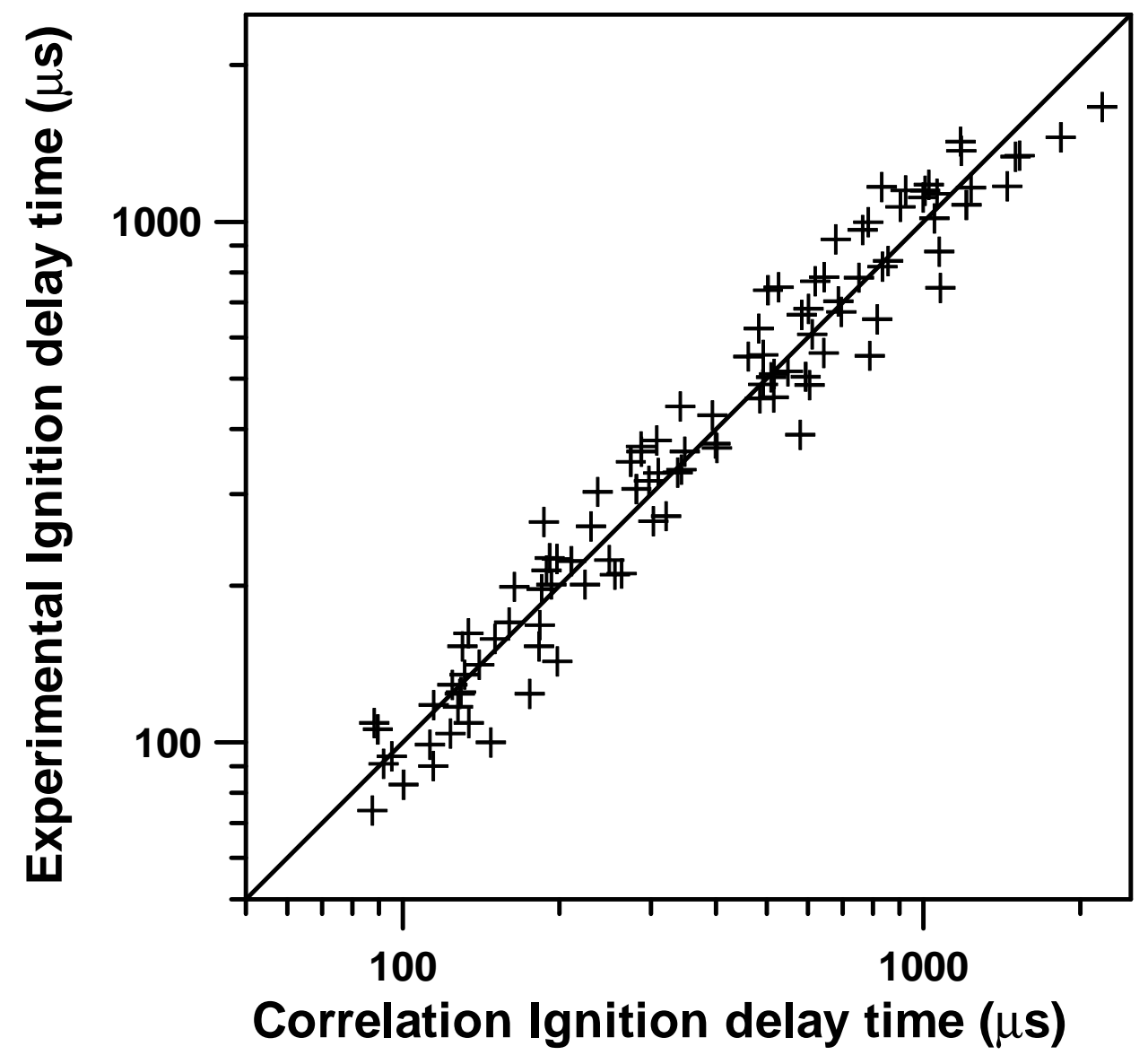

Figure 6: Correlation compared to experiment values for ignition delay times measured during this study.

All of the ignition delay time measurements along with their corresponding conditions behind the reflected shock waves are provided in Table 2.

Table2: Ignition delay times and associated conditions behind reflected shock waves.

\begin{tabular}{|ccc|ccc|}
\hline \multicolumn{2}{|c|}{$0.004 \mathrm{NH}_{3} / 0.006 \mathrm{O}_{2} / 0.99 \mathrm{Ar}$} & \multicolumn{3}{c|}{$0.01143 \mathrm{NH}_{3} / 0.00857 \mathrm{O}_{2} / 0.98 \mathrm{Ar}$} \\
\hline $\mathrm{P}_{5}(\mathrm{~atm})$ & $\mathrm{T}_{5}(\mathrm{~K})$ & $\tau_{\text {ign }}(\mu \mathrm{s})$ & $\mathrm{P}_{5}(\mathrm{~atm})$ & $\mathrm{T}_{5}(\mathrm{~K})$ & $\tau_{\text {ign }}(\mu \mathrm{s})$ \\
\hline 1.58 & 1927 & 1113 & 1.52 & 1827 & 1662 \\
1.57 & 1969 & 998 & 1.43 & 1895 & 1334 \\
1.53 & 2008 & 783 & 1.47 & 1927 & 1078 \\
1.46 & 2023 & 769 & 1.42 & 2029 & 671 \\
1.48 & 2077 & 551 & 1.41 & 2076 & 516 \\
1.44 & 2164 & 380 & 1.38 & 2179 & 330 \\
1.46 & 2175 & 362 & 1.33 & 2253 & 224 \\
1.46 & 2266 & 226 & 1.25 & 2290 & 201 \\
1.43 & 2312 & 170 & 1.28 & 2454 & 90 \\
1.34 & 2389 & 129 & & & \\
\cline { 5 - 6 } 1.29 & 2479 & 91 & 10.9 & 1618 & 1453 \\
\cline { 5 - 6 } & 1626 & 1170 & 10.9 & 1719 & 650 \\
\cline { 5 - 6 } & & & 10.5 & 1768 & 504
\end{tabular}




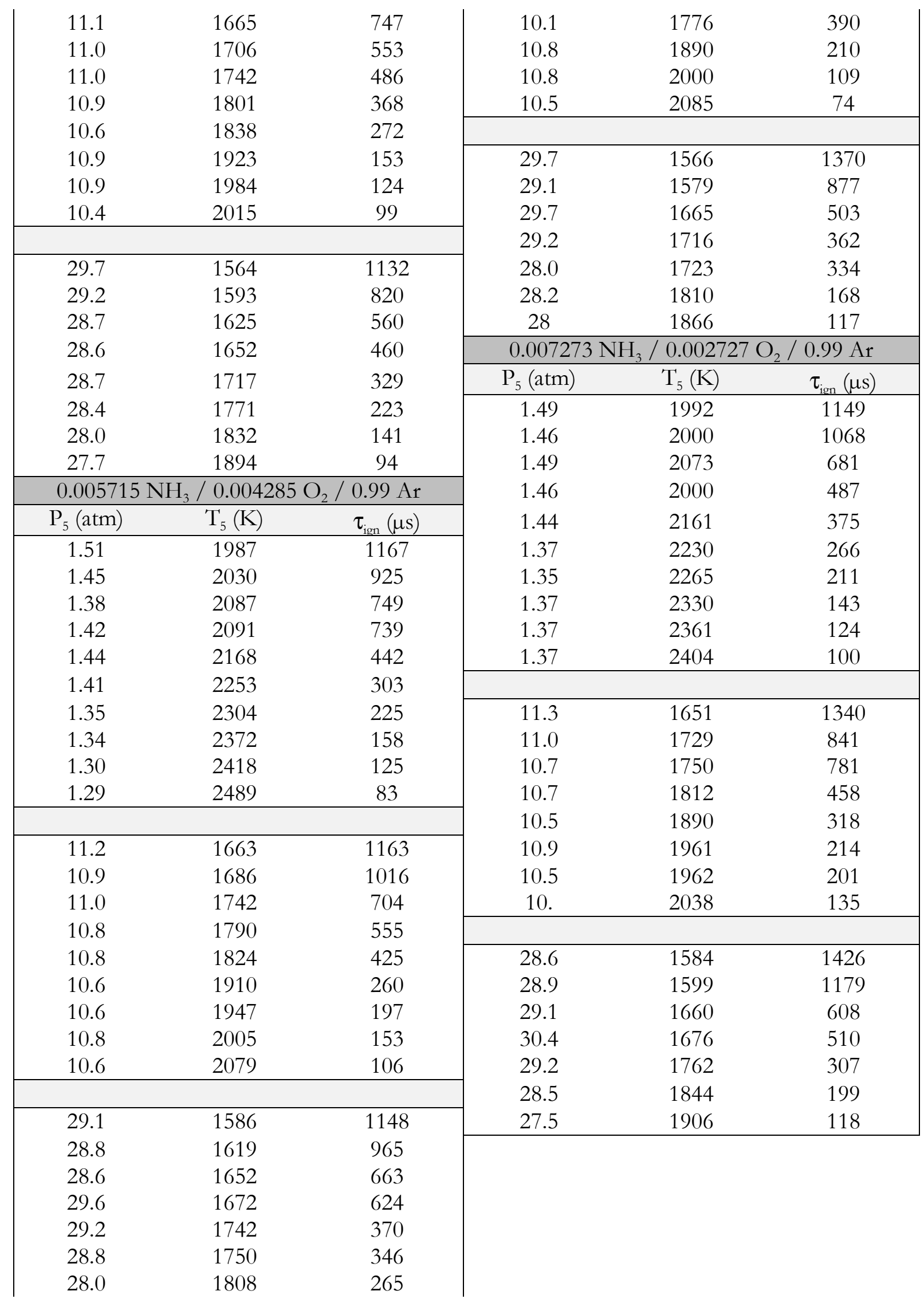




\begin{tabular}{lll|}
27.7 & 1860 & 162 \\
27.9 & 1926 & 109 \\
\hline
\end{tabular}

\section{Comparison with models from the literature}

To assess the validity of the aforementioned detailed kinetics models, data from this study were modeled with mechanisms available in the literature. To compare fairly with the experimental $\mathrm{OH}^{*}$ profile, the $\mathrm{OH}^{*}$ sub-mechanism from Hall and Petersen [55] was merged to these detailed kinetics mechanisms whenever necessary. Due to the large differences observed in some conditions between the computed and experimental ignition delay time and shapes of the $\mathrm{OH}^{*}$ profile, it was found necessary to add the reaction $\mathrm{N}_{2} \mathrm{O}+\mathrm{H} \leftrightarrows \mathrm{N}_{2}+\mathrm{OH}^{*}$ from Hidaka et al. [56] to the $\mathrm{OH}^{*}$ scheme from Hall and Petersen. Figure 7 shows some representative normalized experimental $\mathrm{OH}^{*}$ profiles that have been modeled using the mechanism from Dagaut et al. [48] along with the $\mathrm{OH}^{*}$ chemistry from Hall and Petersen [55] and with and without the aforementioned $\mathrm{OH}^{*}$ formation reaction from Hidaka et al. [56]. As can be seen, this combination of reactions allows for a good comparison between model and experiment for both the profiles and ignition delay times, whereas a strong disagreement in the shape (Fig. 7a and 7c) and in the ignition delay time can be observed without the $\mathrm{OH}^{*}$ formation from the $\mathrm{N}_{2} \mathrm{O}+\mathrm{H} \leftrightarrows \mathrm{N}_{2}+\mathrm{OH}^{*}$ reaction. Note that the normalized $\mathrm{OH}^{*}$ profile does not reach 1 in Fig. 7c because the computed $\mathrm{OH}^{*}$ profile increases and reaches its maximum value well after the time frame of Fig. 7c.

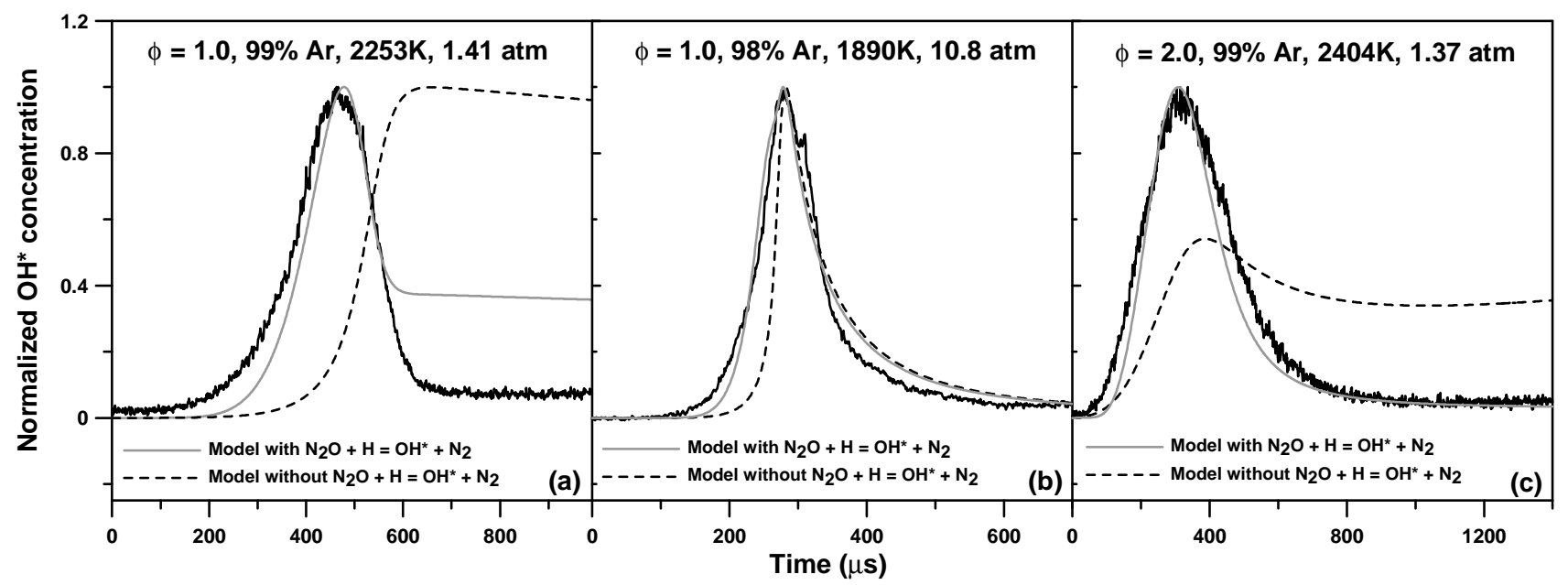

Figure 7: Comparison of the temporal evolution of the experimental and computed $\mathrm{OH}^{*}$ profiles. Model: Dagaut et al. [48] along with the $\mathrm{OH}^{*}$ chemistry from Hall and Petersen [55] with and without the additional $\mathrm{OH}^{*}$ formation reaction from Hidaka et al. [56], for various conditions representative of those investigated during this study.

Using this complete $\mathrm{OH}^{*}$ sub-mechanism, comparisons between some selected and representative data from this study and the models from the literature are visible in Fig. 8. As can be seen in Fig. 8, the mechanism of Dagaut et al. [48] predicts the experimental data with high accuracy regardless of the ammonia concentration, the pressure, or the equivalence ratio. At around $1.4 \mathrm{~atm}$, however, the model tends to be slightly under-reactive but is still the closest to the experimental data. The model of Dagaut and Nicolle [47], although slightly too reactive, also provides acceptable results. As also seen in Fig. 8, the recent model of Klippenstein et al. [50] is close to the prediction of the model from Dagaut and Nicolle at stoichiometric conditions but is too reactive for the fuel-lean and fuel-rich conditions 
investigated. The model from Miller and Bowman [5] generally presents an activation energy that is too high and gives a mediocre prediction of $\tau_{\mathrm{ign}}$. The other mechanisms are somewhat close to each other in terms of predictions (within a factor 3) but are significantly too reactive, in addition to presenting too low of an activation energy. However, it is fair to mention that the mechanism of Duynslaegher et al. [12] was developed for low-pressure conditions only, hence explaining the poor agreement at high pressure, and that the model of Mével et al. [49] is essentially a model that aims primarily to predict the combustion of $\mathrm{H}_{2} / \mathrm{N}_{2} \mathrm{O}$ mixtures that also encompasses an ammonia sub-mechanism.

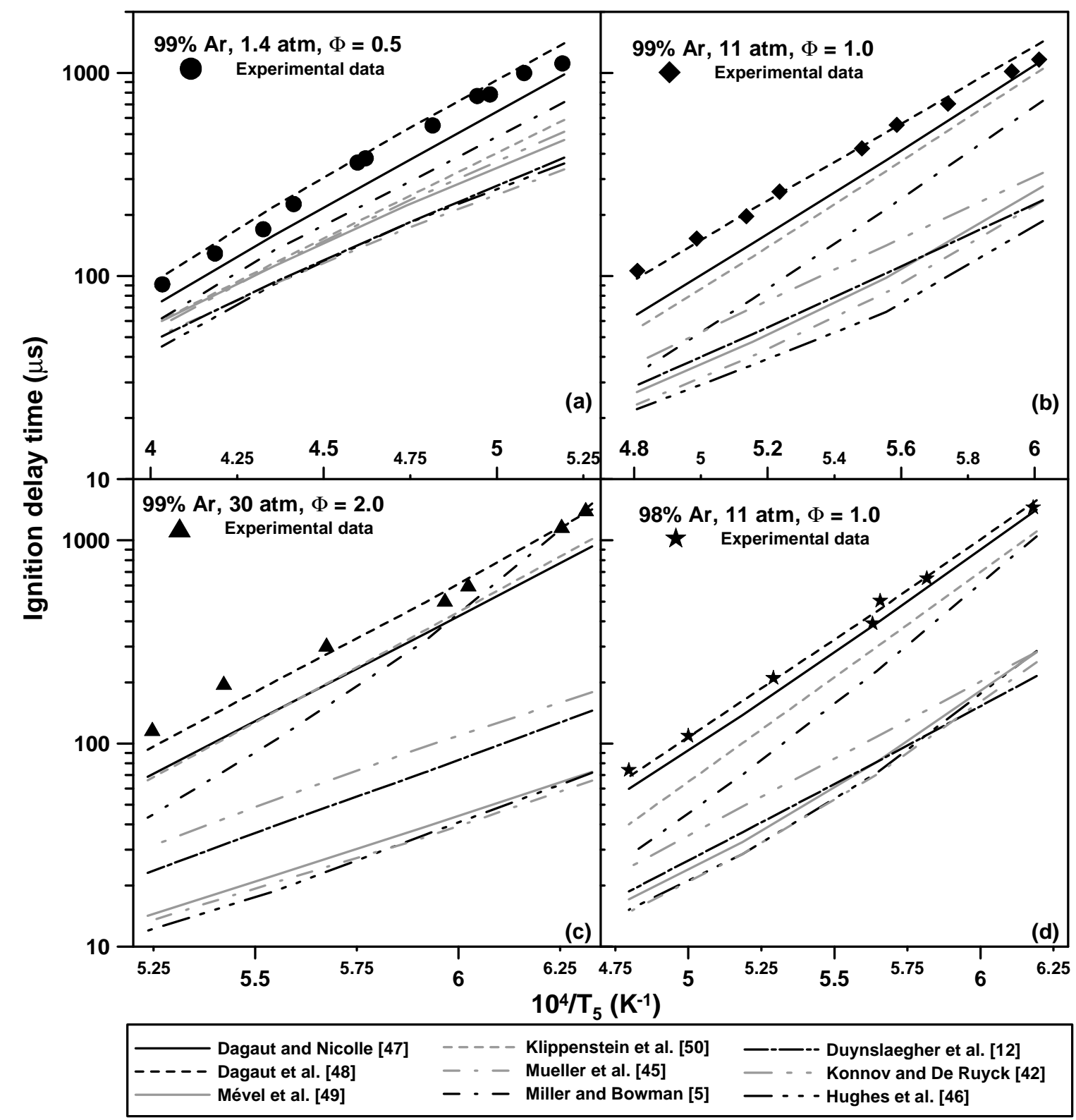

Figure 8: Comparison between models from the literature and selected, representative data from this study. (a): $1.4 \mathrm{~atm}, \phi=0.5,99 \%$ Ar; (b): $11.0 \mathrm{~atm}, \phi=1.0,99 \%$ Ar; (c): $30 \mathrm{~atm}, \phi=2.0,99 \% \mathrm{Ar}$; (d): $11.0 \mathrm{~atm}, \phi=1.0,98 \%$ Ar.

\section{Improvement and validation of a $\mathrm{NH}_{3} / \mathrm{NOx}$ mechanism}


It can be deduced from Fig. 8 that the model from Dagaut et al. [48] is a convenient one for modeling ignition delay times with $\mathrm{NH}_{3}$ over a wide range of conditions. This mechanism was therefore selected as a base to develop a more-comprehensive $\mathrm{NH}_{3} / \mathrm{NOx} / \mathrm{H}_{2}$ model. As mentioned earlier, $\mathrm{NH}_{3}$ can play a great role in the production and control of $\mathrm{NOx}$ species in industrial applications. A great example of the $\mathrm{NOx} / \mathrm{NH}_{3}$ interactions was provided earlier with the $\mathrm{OH}^{*}$ profile predictions, where the $\mathrm{N}_{2} \mathrm{O}$ chemistry was seen to be of great importance for the $\mathrm{NH}_{3}$ combustion, the reaction $\mathrm{N}_{2} \mathrm{O}+\mathrm{H} \leftrightarrows$ $\mathrm{N}_{2}+\mathrm{OH}^{*}$ being critical for the determination of $\tau_{\mathrm{ign}}$ with $\mathrm{NH}_{3}$ data using the $\mathrm{OH}^{*}$ diagnostic. One of the objectives of this study was therefore to assess the validity of the model from Dagaut et al. [48] over $\mathrm{NH}_{3}$ and $\mathrm{NOx}$ data from the literature and to improve the mechanism without deteriorating the good predictions on the shock-tube data from the present study. The predictions from this improved mechanism and the model from Dagaut et al. [48] were also compared to the predictions of the most recent $\mathrm{NH}_{3}$ model from the literature (Klippenstein et al. [50]). Data selected for the model improvement and validation are summarized in Table 3. Note on the flame speed side

Table 3: Literature data selected as a target to validate the model.

\begin{tabular}{|c|c|c|c|}
\hline Target & Type of data & Conditions & Reference \\
\hline \multirow[b]{2}{*}{$\mathrm{NH}_{3}$} & $\tau_{\text {ign }}$ in shock tube $\left(\mathrm{OH}^{*}\right.$ onset $)$ & See Table 1 & This study \\
\hline & $\begin{array}{l}\mathrm{NH}, \mathrm{NH}_{2} \text { profiles and peak } \\
\text { value in shock tube }\end{array}$ & Pyrolysis, $2200-2800 \mathrm{~K}$, around $1 \mathrm{~atm}$ & Davidson et al. [37] \\
\hline $\begin{array}{c}\mathrm{NH}_{3} / \\
\mathrm{N}_{2} \mathrm{O}\end{array}$ & $\tau_{\text {ign }}$ in shock tube (OH onset) & $\begin{array}{l}0.04 \mathrm{NH}_{3} / 0.06 \mathrm{~N}_{2} \mathrm{O} / 0.9 \mathrm{Ar}, 1535-1825 \mathrm{~K} \text {, } \\
3.3-4.4 \mathrm{~atm}\end{array}$ & Drummond [57] \\
\hline \multirow{4}{*}{$\mathrm{N}_{2} \mathrm{O}$} & $\tau_{\text {ign }}$ in shock tube $\left(\mathrm{OH}^{*}\right.$ onset $)$ & $\begin{array}{l}0.01 \mathrm{H}_{2} / 0.01 \mathrm{O}_{2} / 0.98 \mathrm{Ar}+0,100,400, \\
1600 \text {, and } 3200 \mathrm{ppm} \text { of } \mathrm{N}_{2} \mathrm{O}, 1.7-32 \mathrm{~atm}\end{array}$ & Mathieu et al. [58] \\
\hline & $\begin{array}{l}\tau_{\text {ign }} \text { in shock tube (time at } 50 \% \\
\text { of maximum } \mathrm{OH}^{*} \text { signal) }\end{array}$ & $\begin{array}{l}\mathrm{H}_{2} / \mathrm{N}_{2} \mathrm{O} \text { mixtures, } 1300-2000 \mathrm{~K}, \\
0.5<\phi<2.0,98-99 \% \mathrm{Ar}, 3-9 \mathrm{~atm}\end{array}$ & Mével et al. [49] \\
\hline & $\begin{array}{l}\text { Time at } 50 \% \text { and } 80 \% \text { of } \mathrm{N}_{2} \mathrm{O} \\
\text { consumption }\end{array}$ & $\begin{array}{l}\mathrm{N}_{2} \mathrm{O} / \mathrm{H}_{2} / \mathrm{Ar} \text { mixtures, } 1400-2000 \mathrm{~K}, \\
3 \mathrm{~atm}\end{array}$ & Hidaka et al. [59] \\
\hline & $\begin{array}{l}\text { Time at the peak of } \mathrm{OH}^{*} \\
\text { profile }\end{array}$ & $\begin{array}{l}0.005 \mathrm{H}_{2} / 0.01 \mathrm{~N}_{2} \mathrm{O} / 0.03 \mathrm{CO} / 0.9595 \mathrm{Ar}, \\
1654-2221 \mathrm{~K}, 1.4 \text { and } 10 \mathrm{~atm}\end{array}$ & Kopp et al. [60] \\
\hline \multirow{2}{*}{$\mathrm{NO}_{2}$} & $\tau_{\text {ign }}$ in shock tube (OH* onset) & $\begin{array}{l}0.01 \mathrm{H}_{2} / 0.01 \mathrm{O}_{2} / 0.98 \mathrm{Ar}+0,100,400, \\
\text { and } 1600 \mathrm{ppm} \text { of } \mathrm{NO}_{2}, 1.7-33 \mathrm{~atm}\end{array}$ & Mathieu et al. [61] \\
\hline & $\begin{array}{l}\mathrm{H}_{2} \text { oxidation with } \mathrm{NO} \text { or } \mathrm{NO}_{2} \\
\text { addition in a jet stirred reactor }\end{array}$ & $\begin{array}{l}1 \& 10 \mathrm{~atm}, 0-50 \mathrm{ppm} \mathrm{NO}_{2}, 0-200 \mathrm{ppm} \\
\mathrm{NO}, 10000 \mathrm{ppm} \mathrm{H}_{2} \text { in } \mathrm{N}_{2}\end{array}$ & Dayma and Dagaut [62] \\
\hline \multirow{2}{*}{$\mathrm{HCN}$} & $\begin{array}{l}\tau_{\text {ign }} \text { in shock tube (time at } 10 \% \\
\text { peak } O H \text { ) }\end{array}$ & $\begin{array}{l}1 \% \mathrm{HCN} / 1 \% \mathrm{O}_{2} \text { in } \mathrm{Ar}, 1885-2630 \mathrm{~K}, 1 \\
\mathrm{~atm}\end{array}$ & Higashihara et al. [63] \\
\hline & $\mathrm{N}, \mathrm{O}, \mathrm{H}$ absorption traces & $\begin{array}{l}50-100 \mathrm{ppm} \mathrm{HCN} / 50-1000 \mathrm{ppm} \mathrm{O}_{2} \text { in } \\
\mathrm{Ar}, 2600-2836 \mathrm{~K}, 1.69-1.82 \mathrm{~atm}\end{array}$ & Thielen and Roth [64] \\
\hline
\end{tabular}

The first improvement to the mechanism from Dagaut et al. [48] was to update the $\mathrm{H}_{2} / \mathrm{O}_{2}$ chemistry with the recent $\mathrm{H}_{2} / \mathrm{CO} / \mathrm{O}_{2}$ model from Kéromnès et al. [65]. This replacement of $\mathrm{H}_{2} / \mathrm{O}_{2}$ chemistry has nearly no effect on the predictions for the ignition delay times with $\mathrm{NH}_{3}$ from the present study but improves the predictions against some literature data involving mixtures with $\mathrm{H}_{2}$ and $\mathrm{O}_{2}$. The second stage of the mechanism development consisted of improving the $\mathrm{N}_{2} \mathrm{O}$ predictions, to validate the model on the particular link between $\mathrm{NH}_{3}$ and $\mathrm{N}_{2} \mathrm{O}$ previously observed with $\mathrm{OH}^{*}$ profiles. Reactions involving $\mathrm{N}_{2} \mathrm{O}$ have then been replaced by the ones selected in the $\mathrm{H}_{2} / \mathrm{N}_{2} \mathrm{O}$ mechanism proposed recently by the authors in Mathieu et al. [58]. The reactions involving $\mathrm{NO}_{2}$ in the model proposed herein have been selected based on the work done in Mathieu et al. [61] where it has been seen that the $\mathrm{NO}_{2}$ 
chemistry from Dayma and Dagaut [62] with the high-pressure updates from Sivaramakrishnan et al. [68] and with the reaction rate coefficient for the reaction $\mathrm{H}_{2}+\mathrm{NO}_{2} \leftrightarrows \mathrm{HONO}+\mathrm{H}$ from Parks et al. [69] accurately modeling these results. Table 4 presents the sub-mechanisms used to assemble the mechanism proposed in the present study. To provide further details on the model proposed in this paper, the reactions that have been modified in the model from Dagaut et al. [48] are listed in Table 5 (apart from the $\mathrm{H}_{2} / \mathrm{CO}$ chemistry integrally coming from Kéromnès et al. [65]).

Table 4: List of the sub-mechanisms used to assemble the mechanism proposed in the present study.

\begin{tabular}{|l|l|}
\hline Sub-mechanism & Reference \\
\hline $\mathrm{H}_{2} / \mathrm{CO}$ & Kéromnès et al. [65] \\
\hline $\mathrm{NH}_{3}$ & Dagaut et al. [48] \\
\hline $\mathrm{HCN}$ & Dagaut et al. [48] \\
\hline $\mathrm{N}_{2} \mathrm{O}$ & Mathieu et al. [58] \\
\hline $\mathrm{NO}_{2}$ & $\begin{array}{l}\text { Dayma and Dagaut [62] with high-pressure } \\
\text { updates from Sivaramakrishnan et al. [68] }\end{array}$ \\
\hline $\mathrm{NNH}$ & Klippenstein et al. [50] \\
\hline
\end{tabular}

Table 5: List of reactions that have been modified in or added to the mechanism from Dagaut et al. [48] (in addition to the change in the $\mathrm{H}_{2} / \mathrm{CO}$ chemistry from Kéromnès et al. [65]).

\begin{tabular}{|c|c|c|c|c|}
\hline \multirow{2}{*}{ Reaction } & \multicolumn{3}{|c|}{ Reaction Rate (cm, mol, s, cal) } & \multirow{2}{*}{ Source } \\
\hline & $\mathrm{A}$ & $n$ & $\mathrm{E}$ & \\
\hline \multirow{2}{*}{$\begin{array}{l}\mathrm{N}_{2} \mathrm{O}+\mathrm{M} \leftrightarrows \mathrm{N}_{2}+\mathrm{O}+\mathrm{M} \\
\text { Low pressure limit }\end{array}$} & $9.9 \times 10^{10}$ & 0 & 57960 & \multirow{2}{*}{ [66] } \\
\hline & $6.62 \times 10^{14}$ & 0 & 57500 & \\
\hline \multirow{2}{*}{$\begin{array}{l}\mathrm{N}_{2} \mathrm{O}+\mathrm{H} \leftrightarrows \mathrm{N}_{2}+\mathrm{OH} \\
\text { duplicate }\end{array}$} & $3.31 \times 10^{10}$ & 0 & 5090 & \multirow{2}{*}{ [66] } \\
\hline & $7.83 \times 10^{14}$ & 0 & 19390 & \\
\hline $\mathrm{N}_{2} \mathrm{O}+\mathrm{OH} \leftrightarrows \mathrm{N}_{2}+\mathrm{HO}_{2}$ & $2 \times 10^{12}$ & 0 & 40000 & [49] \\
\hline $\mathrm{NO}_{3} \leftrightarrows \mathrm{NO}+\mathrm{O}_{2}$ & $2.5 \times 10^{6}$ & 0 & 12120 & [67] \\
\hline $\mathrm{NO}_{3}+\mathrm{NO}_{3} \leftrightarrows \mathrm{NO}_{2}+\mathrm{NO}_{2}+\mathrm{O}_{2}$ & $5.12 \times 10^{11}$ & 0 & 4870 & [67] \\
\hline $\mathrm{N}_{2} \mathrm{O}_{4}(+\mathrm{M}) \leftrightarrows \mathrm{NO}_{2}+\mathrm{NO}_{2}(+\mathrm{M})$ & $4.05 \times 10^{18}$ & -1.1 & 12840 & \multirow{2}{*}{ [67] } \\
\hline Low pressure limit & $1.96 \times 28$ & -3.8 & 12840 & \\
\hline $\mathrm{N}_{2} \mathrm{O}_{4}+\mathrm{O} \leftrightarrows \mathrm{N}_{2} \mathrm{O}_{3}+\mathrm{O}_{2}$ & $1.21 \times 10^{12}$ & 0 & 0 & [67] \\
\hline $\mathrm{N}_{2} \mathrm{O}_{3}+\mathrm{O} \leftrightarrows \mathrm{NO}_{2}+\mathrm{NO}_{2}$ & $2.7 \times 10^{11}$ & 0 & 0 & [67] \\
\hline $\mathrm{N}_{2}+\mathrm{M \leftrightarrows} \mathrm{N}+\mathrm{N}+\mathrm{M}$ & $1.89 \times 10^{18}$ & -0.85 & 224950 & [68] \\
\hline $\mathrm{N}+\mathrm{O}+\mathrm{M} \leftrightarrows \mathrm{NO}+\mathrm{M}$ & $7.6 \times 10^{14}$ & -0.1 & -1770 & [68] \\
\hline $\mathrm{N}_{2}+\mathrm{O} \leftrightarrows \mathrm{N}+\mathrm{NO}$ & $1 \times 10^{14}$ & 0 & 75490 & [68] \\
\hline $\mathrm{NO}+\mathrm{OH}(+\mathrm{M}) \leftrightarrows \mathrm{HONO}(+\mathrm{M})$ & $1.99 \times 10^{12}$ & -0.05 & -721 & [68] \\
\hline $\mathrm{NO}+\mathrm{H}+\mathrm{M} \leftrightarrows \mathrm{HNO}+\mathrm{M}$ & $3 \times 10^{20}$ & -1.75 & 0 & [68] \\
\hline $\mathrm{NO}_{2}+\mathrm{H}_{2} \leftrightarrows \mathrm{HONO}+\mathrm{H}$ & $1.3 \times 10^{4}$ & 2.76 & 29770 & [69] \\
\hline $\mathrm{NO}_{2}+\mathrm{M} \leftrightarrows \mathrm{NO}+\mathrm{O}+\mathrm{M}$ & $1.1 \times 10^{16}$ & 0 & 66000 & [68] \\
\hline $\mathrm{NO}_{2}+\mathrm{NO}_{2} \leftrightarrows \mathrm{NO}+\mathrm{NO}+\mathrm{O}_{2}$ & $2 \times 10^{12}$ & 0 & 26825 & {$[68]$} \\
\hline $\mathrm{NO}_{2}+\mathrm{HO}_{2} \leftrightarrows \mathrm{HONO}+\mathrm{O}_{2}$ & 1.91 & 3.32 & 3044 & {$[68]$} \\
\hline $\mathrm{NO}_{2}+\mathrm{NO} \leftrightarrows \mathrm{N}_{2} \mathrm{O}+\mathrm{O}_{2}$ & $1 \times 10^{12}$ & 0 & 60000 & [68] \\
\hline $\mathrm{HONO}+\mathrm{OH} \leftrightarrows \mathrm{NO}_{2}+\mathrm{H}_{2} \mathrm{O}$ & $1.3 \times 10^{10}$ & 1 & 135 & [68] \\
\hline $\mathrm{HNO}+\mathrm{O} \leftrightarrows \mathrm{NO}+\mathrm{OH}$ & $1 \times 10^{13}$ & 0 & 0 & [68] \\
\hline $\mathrm{HNO}+\mathrm{NO}_{2} \leftrightarrows \mathrm{NO}+\mathrm{HONO}$ & $4.42 \times 10^{4}$ & 2.6 & 4060 & {$[68]$} \\
\hline $\mathrm{HNO}+\mathrm{HNO} \leftrightarrows \mathrm{N}_{2} \mathrm{O}+\mathrm{H}_{2} \mathrm{O}$ & $3.95 \times 10^{12}$ & 0 & 5000 & {$[68]$} \\
\hline $\mathrm{HNO}+\mathrm{NO} \leftrightarrows \mathrm{N}_{2} \mathrm{O}+\mathrm{OH}$ & $2 \times 10^{12}$ & 0 & 26000 & [68] \\
\hline
\end{tabular}




\begin{tabular}{|c|c|c|c|c|}
\hline $\mathrm{N}+\mathrm{NO}_{2} \leftrightarrows \mathrm{N}_{2} \mathrm{O}+\mathrm{O}$ & $1.8 \times 10^{12}$ & 0 & 0 & [68] \\
\hline $\mathrm{N}+\mathrm{O}_{2} \leftrightarrows \mathrm{NO}+\mathrm{O}$ & $6.4 \times 10^{9}$ & 1 & 6280 & [68] \\
\hline $\mathrm{N}+\mathrm{OH} \leftrightarrows \mathrm{NO}+\mathrm{H}$ & $3.8 \times 10^{13}$ & 0 & 0 & {$[68]$} \\
\hline $\mathrm{N}_{2} \mathrm{O}+\mathrm{N} \leftrightarrows \mathrm{N}_{2}+\mathrm{NO}$ & $1 \times 10^{13}$ & 0 & 19870 & [68] \\
\hline $\mathrm{H}_{2} \mathrm{NO}+\mathrm{M} \leftrightarrows \mathrm{H}_{2}+\mathrm{NO}+\mathrm{M}$ & $3.83 \times 10^{27}$ & -4.29 & 60300 & [68] \\
\hline $\mathrm{HO}_{2}+\mathrm{NO}+\mathrm{M} \leftrightarrows \mathrm{HONO}_{2}+\mathrm{M}$ & $2.23 \times 10^{12}$ & -3.5 & 2200 & [68] \\
\hline $\mathrm{HNO}_{2}+\mathrm{H} \leftrightarrows \mathrm{NO}_{2}+\mathrm{H}_{2}$ & $2.4 \times 10^{8}$ & 1.5 & 5087 & [68] \\
\hline $\mathrm{HNO}_{2}+\mathrm{O} \leftrightarrows \mathrm{NO}_{2}+\mathrm{OH}$ & $1.7 \times 10^{8}$ & 1.5 & 3020 & [68] \\
\hline $\mathrm{HNO}_{2}+\mathrm{OH} \leftrightarrows \mathrm{NO}_{2}+\mathrm{H}_{2} \mathrm{O}$ & $1.2 \times 10^{6}$ & 2 & -596 & [68] \\
\hline $\mathrm{HNO}_{2} \leftrightarrows \mathrm{HONO}$ & $1.3 \times 10^{29}$ & -5.47 & 52814 & [68] \\
\hline $\mathrm{HONO}+\mathrm{NH}_{2} \leftrightarrows \mathrm{NO}_{2}+\mathrm{NH}_{3}$ & 71.1 & 3.02 & -4941 & [68] \\
\hline $\mathrm{HNO}+\mathrm{N} \leftrightarrows \mathrm{NO}+\mathrm{NH}$ & $1 \times 10^{13}$ & 0 & 1990 & [68] \\
\hline $\mathrm{NH}+\mathrm{H} \leftrightarrows \mathrm{N}+\mathrm{H}_{2}$ & $1 \times 10^{14}$ & 0 & 0 & [5] \\
\hline $\mathrm{NNH}+\mathrm{O} \leftrightarrows \mathrm{NH}+\mathrm{NO}$ & $5.2 \times 10^{11}$ & 0.388 & -409 & {$[50]$} \\
\hline $\mathrm{NNH}+\mathrm{O} \leftrightarrows \mathrm{N}_{2}+\mathrm{OH}$ & $1.2 \times 10^{13}$ & 0.145 & -217 & [50] \\
\hline $\mathrm{NH}+\mathrm{NO} \leftrightarrows \mathrm{N}_{2} \mathrm{O}+\mathrm{H}$ & $1.8 \times 10^{14}$ & -0.351 & -244 & [50] \\
\hline $\mathrm{NH}_{2}+\mathrm{NO} \leftrightarrows \mathrm{NNH}+\mathrm{OH}$ & $3.1 \times 10^{13}$ & -0.48 & 1180 & [50] \\
\hline
\end{tabular}

\section{$\mathrm{N}_{2} \mathrm{O}$ sub-mechanism validation}

Figures 9-13 show comparisons between the $\mathrm{N}_{2} \mathrm{O}$ data selected (Table 3) and the models selected (Table 4). Hidaka et al. [59] followed the temporal evolution of the $\mathrm{N}_{2} \mathrm{O}$ concentration for a $\mathrm{N}_{2} \mathrm{O} / \mathrm{H}_{2}$ mixture diluted in Ar. They determined the times at which the concentration of $\mathrm{N}_{2} \mathrm{O}$ was 80 and $50 \%$ of the initial concentration ( $t_{80}$ and $t_{50}$, respectively) for several temperatures. As can be seen in Fig. 9, the model from the present study predicts $t_{80}$ with accuracy over the entire range of temperature, while $t_{50}$ is correctly reproduced overall, especially for the lowest temperatures. The models of Dagaut et al. and Klippenstein et al. are however predicting $t_{50}$ and $t_{80}$ that are too long. Compared to the $t_{80}$ and $t_{50}$ from the model proposed in this study, predictions from the model from Dagaut et al. [48] are around 25\% longer, and this difference reaches 50-60\% with the model from Klippenstein et al. [50]. 


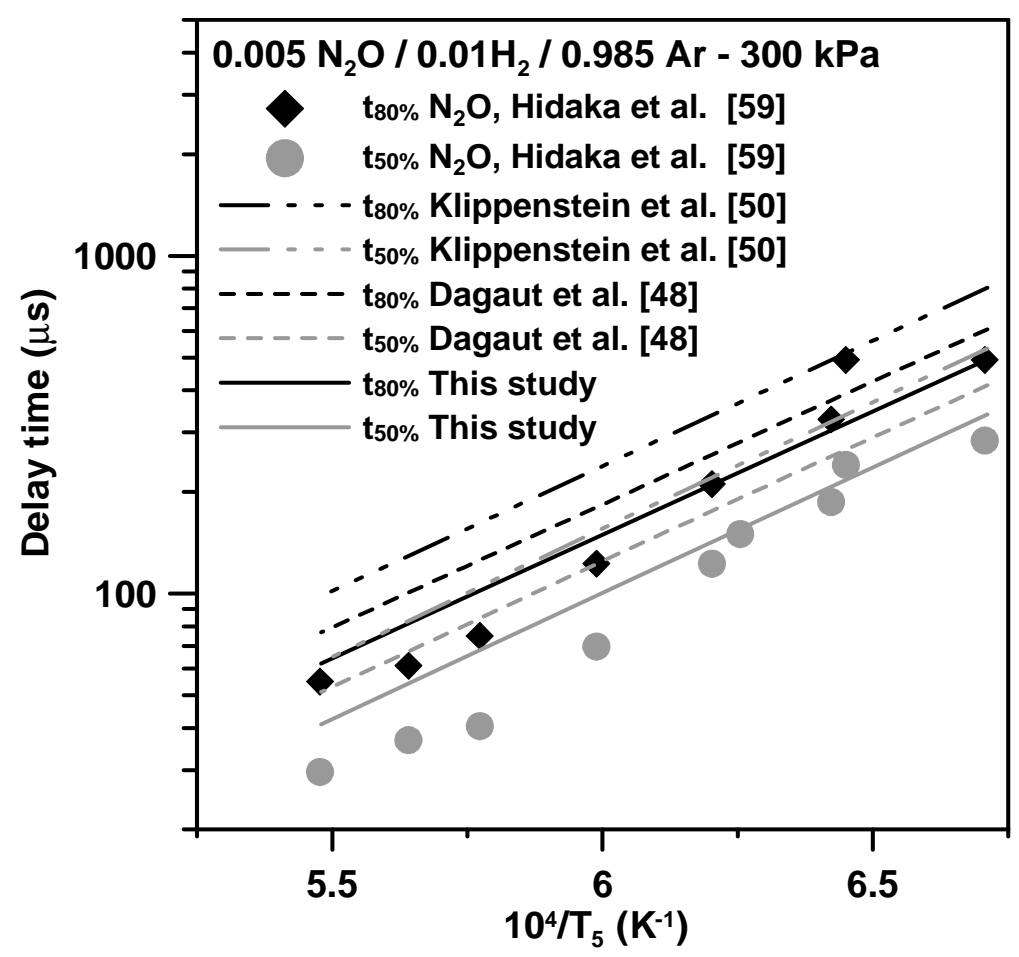

Figure 9: Comparison between experimental data of Hidaka et al. [59] and the various model predictions for the time at which 50 and $80 \%$ of the $\mathrm{N}_{2} \mathrm{O}$ is consumed at various temperatures for a 0.005 $\mathrm{N}_{2} \mathrm{O} / 0.01 \mathrm{H}_{2} / 0.985$ Ar mixture at $300 \mathrm{kPa}$.

The comparison between the models and the ignition delay time measurements from $\mathrm{N}_{2} / \mathrm{N}_{2} \mathrm{O}$ mixtures diluted in Ar from Mével et al. [49] are visible in Fig. 10. Results are the mostly the same for the two dilution levels at around $3 \mathrm{~atm}$ (Figs. 10a and 10b) or at high pressure (Fig. 10c): the models are close to each other and in good agreement, overall, with the data. The model from the present study presents the shortest ignition delay time predictions, which makes predictions in better agreement with the data on the low-temperature side. However, the agreement with the data is not as good as with the other models at high temperature, although the difference with the experimental data is always on the order of a few tenths of a microsecond for the highest temperatures, which should largely be well within the experimental error factor. 


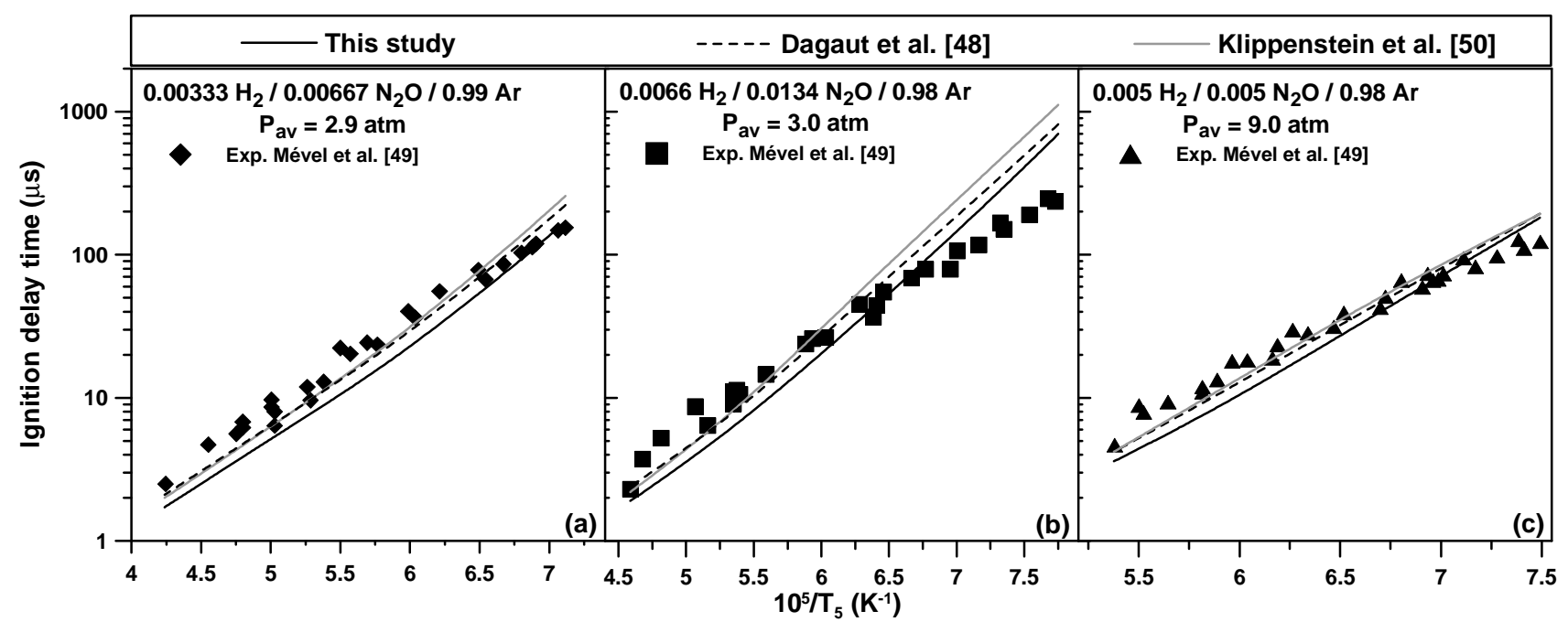

Figure 10: Comparison between the experimental data of Mével et al. [49] and the model predictions.

The comparison between the models and the data from Mathieu et al. [58] with a $\mathrm{H}_{2} / \mathrm{O}_{2}$ mixture seeded with $\mathrm{N}_{2} \mathrm{O}$ is visible in Fig. 11. As can be seen from this figure, the model from the present study predicts with high accuracy the ignition delay times over the entire range of temperature for the 3 pressure conditions investigated. At around 1.9 atm (Fig. 11a), one can see that the other models from the literature deviate rapidly from the experiments below $1100 \mathrm{~K}$, where a difference by a factor of up to 5 is observed around $1000 \mathrm{~K}$. For the intermediate pressure investigated (Fig. 11b), the literature models are in acceptable agreement with the data above $1200 \mathrm{~K}$ but significantly over-predict the ignition delay time below this temperature, by a factor 3 or more. A factor of 3 (Dagaut et al. [48]) to 4-5 (Klippenstein et al. [50]) was observed between the model and the data at the highest pressure investigated (Fig. 11c).

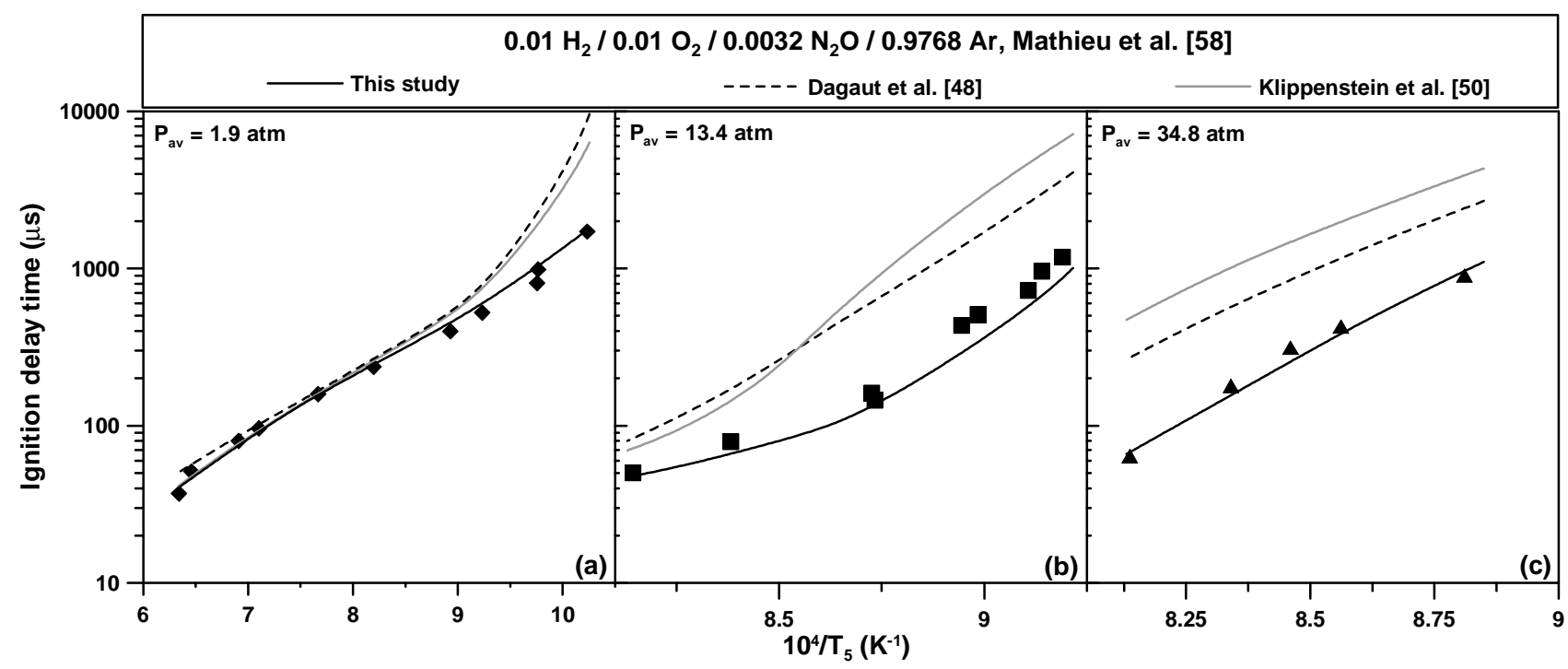

Figure 11: Comparison between models and experiments from Mathieu et al. [58] for the ignition delay times of a $0.01 \mathrm{H}_{2} / 0.01 \mathrm{O}_{2} / 0.0032 \mathrm{~N}_{2} \mathrm{O}$ mixture diluted in $\mathrm{Ar}$ at (a) around $1.9 \mathrm{~atm}$, (b) around 13.4 atm, and (c) around $34.8 \mathrm{~atm}$. 
For the time-to-peak delays determined by Kopp et al. [60], it is visible in Fig. 12 that the model of the present study predicts the shortest delays at around $1.4 \mathrm{~atm}$, the three models being very close in terms of predictions above $1900 \mathrm{~K}$. Below this temperature, the peak times predicted by the models from the literature are increasing more rapidly than observed experimentally, which is not the case for the model of the present study. The general trend of the data at $10.4 \mathrm{~atm}$ is also well captured by the present model as well as by the model from Klippenstein et al. [50]. The model of Dagaut et al. [48], however, does not reproduce the experimental trend below $1900 \mathrm{~K}$ at this higher-pressure condition.

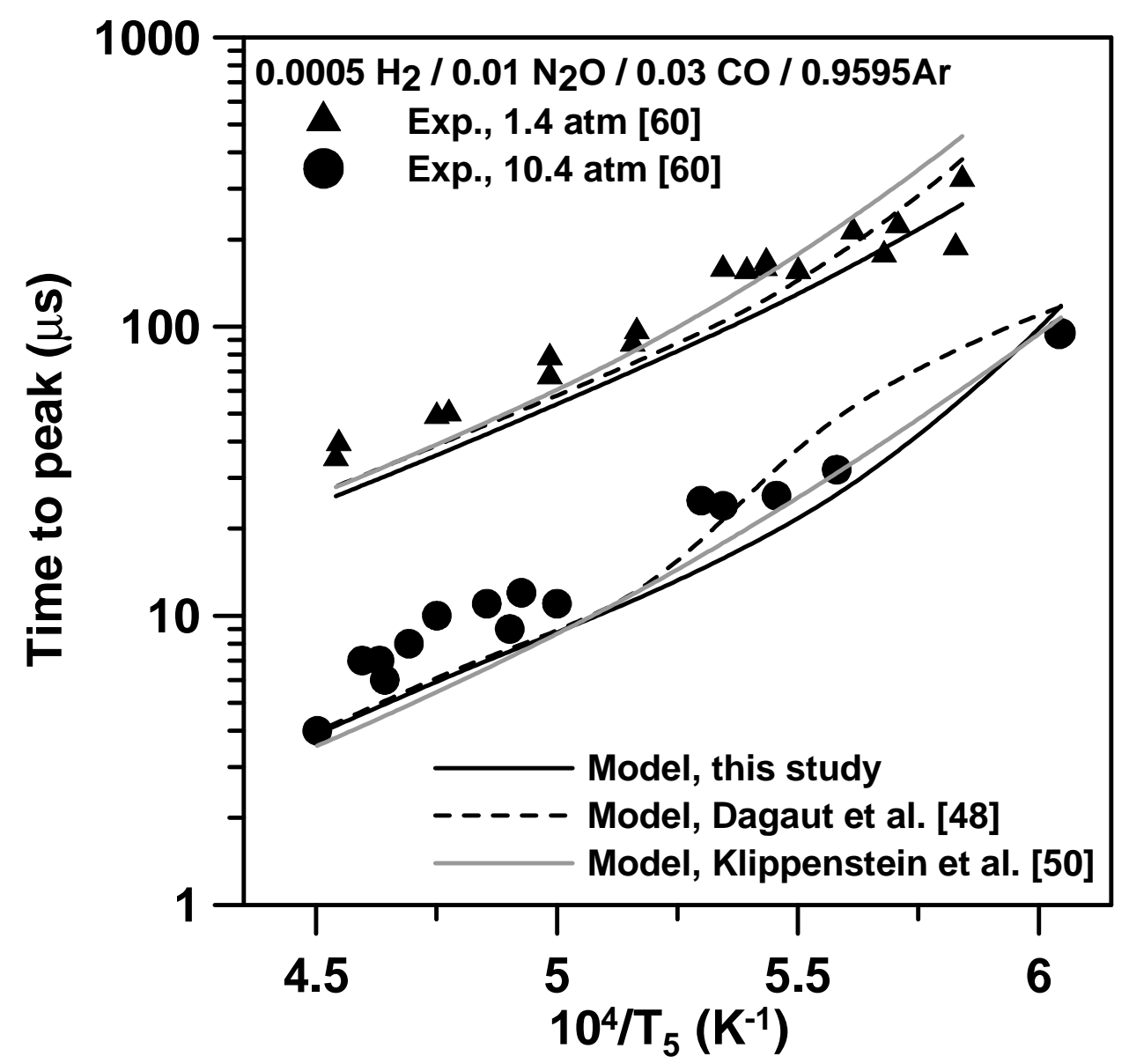

Figure 12: Comparison between experimental data of Kopp et al. [60] and the various model predictions for the time at which the peak of the $\mathrm{OH}^{*}$ profile was observed for a mixture of $0.0005 \mathrm{H}_{2} / 0.01$ $\mathrm{N}_{2} \mathrm{O} / 0.03 \mathrm{CO} / 0.9595 \mathrm{Ar}$ at around 1.4 and $10.4 \mathrm{~atm}$.

Note that the data from Mével et al. [49], Mathieu et al. [58], and Kopp et al. [60] have all been determined from $\mathrm{OH}^{*}$ signals but at different locations of the signal: at the onset of the signal in Mathieu et al. [58], at 50\% of the maximum intensity of the signal in Mével et al. [49] and at the time to peak for Kopp et al. [60]. The fact the model from the present study provides good predictions for all three of these datasets indicates that the key features of the $\mathrm{OH}^{*}$ profiles (which depend on the accuracy of the fundamental stage chemistry) are well captured by the model, for different mixtures and over large ranges of pressure and temperature. Details on the choices for the reactions selected for the $\mathrm{N}_{2} \mathrm{O}$ sub-mechanism can be found in Mathieu et al. [58].

$\mathrm{NO} / \mathrm{NO}_{2}$ sub-mechanism validation 
The next stage of the mechanism development consisted of verifying the validity of the $\mathrm{NO} / \mathrm{NO}_{2}$ sub-mechanism. However, the amount of data involving $\mathrm{NO} / \mathrm{NO}_{2}$ that can be used to validate the combined mechanism herein is significantly smaller than for $\mathrm{N}_{2} \mathrm{O}$. Most of the literature data are focused on interactions between $\mathrm{NO}$ or $\mathrm{NO}_{2}$ with hydrocarbons, which is beyond the scope of this study. To validate this sub-mechanism, the ignition delay times measured in a shock tube with $\mathrm{H}_{2} / \mathrm{O}_{2} / \mathrm{NO}_{2}$ mixtures in Ar by Mathieu et al. [61] was used. As can be seen in Fig. 13, the data from Mathieu et al. [61] are well predicted by the various models, expect for the data at $33 \mathrm{~atm}$ (Fig. 13c) for which the model of Dagaut et al. [48] is too reactive, especially on the lower-temperature side. At this high-pressure condition, the two other models yield nearly identical results. For the intermediate pressure, Fig. 13b, the model of the present study exhibits very accurate predictions (within the size of the data symbols) over the entire range of temperature; whereas the model of Dagaut et al. is slightly over-reactive, and the model from Klippenstein et al. presents ignition delay times that are slightly too long on the lower-temperature side. For the lowest pressure condition investigated, Fig. 13a, the model from Dagaut et al. presents the best overall agreement with the data, especially on the lowertemperature side where the model of the present study is slightly under-reactive, but the present model is nonetheless also within the scatter of data over most of the temperature range.

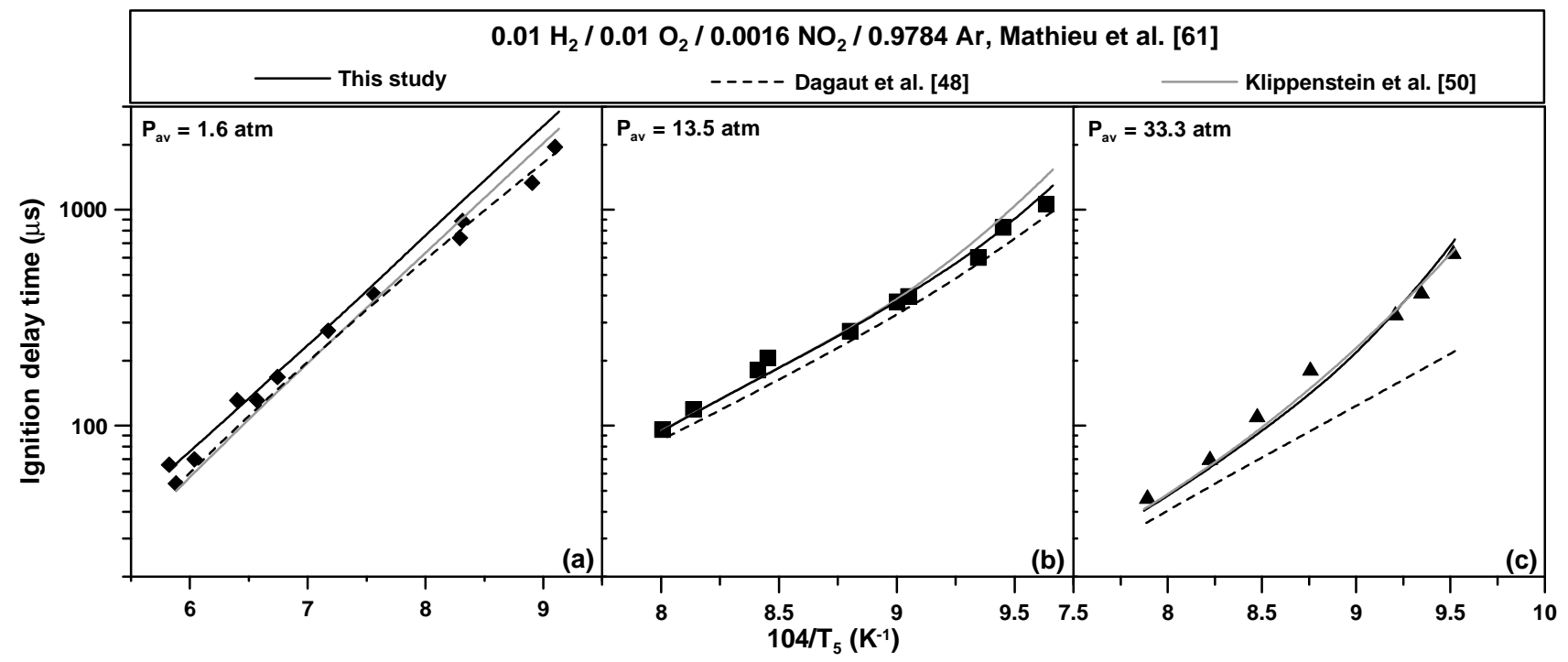

Figure 13: Comparison between models and experiments from Mathieu et al. [61] for the ignition delay times of a $0.01 \mathrm{H}_{2} / 0.01 \mathrm{O}_{2} / 0.0016 \mathrm{NO}_{2}$ mixture diluted in $\mathrm{Ar}$ at (a) around $1.6 \mathrm{~atm}$, (b) around 13.5 atm, and (c) around $33.3 \mathrm{~atm}$.

Jet-stirred reactor data for $\mathrm{H}_{2} / \mathrm{O}_{2}$ mixtures seeded with either $\mathrm{NO}$ or $\mathrm{NO}_{2}$ at various equivalence ratios from Dayma and Dagaut [62] have also been used to validate the model. These data have been modeled using the SENKIN module [70] of the PSR computer code [71]. Comparisons between the models and the data for some representative mixtures and conditions are presented in Fig. 14.

Evolutions with the temperature for $\mathrm{H}_{2}$ and $\mathrm{H}_{2} \mathrm{O}$, and $\mathrm{NO}$ and $\mathrm{NO}_{2}$ at fuel lean conditions $(\phi=0.5)$ and in the presence of $220 \mathrm{ppm}$ of $\mathrm{NO}$ are visible in Fig. 14a and Fig. 14b, respectively. At these conditions, the model of Dagaut et al. [48] is slightly over-reactive as the $\mathrm{H}_{2}$ consumption (and the corresponding $\mathrm{H}_{2} \mathrm{O}$ formation) starts at a temperature slightly lower than observed experimentally. The experimental profiles for these two species are better reproduced by the model proposed in this study and by the model of Klippenstein et al. [50], especially for temperatures below $875 \mathrm{~K}$. The overreactivity of the model from Dagaut et al. is also visible on the $\mathrm{NO} / \mathrm{NO}_{2}$ profiles (Fig. 14b), where the 
conversion of $\mathrm{NO}$ to $\mathrm{NO}_{2}$ starts about $40 \mathrm{~K}$ lower than the experiments. The $\mathrm{NO}$ and $\mathrm{NO}_{2}$ profiles are well predicted by the model presented in this study, both in terms of temperature dependence and in the amplitudes of the humps. The model of Klippenstein et al. also presents good predictions, although the conversion of $\mathrm{NO}$ to $\mathrm{NO}_{2}$ starts at slightly too-high of a temperature, and the amount of NO consumed at the peak is a little too high as well.

For the same mixture but at a fuel-rich condition $(\phi=1.5)$, the $\mathrm{H}_{2}$ and $\mathrm{H}_{2} \mathrm{O}$ profiles (Fig. 14c) are overall well predicted by the three models considered. The model from the present study captures the $\mathrm{H}_{2} \mathrm{O}$ profile and low-temperature side of the $\mathrm{H}_{2}$ profile the best, but the other models considered are closer to the $\mathrm{H}_{2}$ data for temperatures above $825 \mathrm{~K}$. As for the previous case, the first peaks of $\mathrm{NO}$ consumption $/ \mathrm{NO}_{2}$ formation, around $800 \mathrm{~K}$, is better captured by the model of the present study (Fig. 14d). However, at temperatures higher than $900 \mathrm{~K}$, the two other models are closer to the experimental data for the NO profile; although the second hump observed around $1025 \mathrm{~K}$ is captured by the model of the present study only. When $\mathrm{NO}_{2}$ was added to the mixture, all models are noticeably over-reactive when compared to the experimental $\mathrm{H}_{2}$ and $\mathrm{H}_{2} \mathrm{O}$ profiles (Fig. 14e). As seen, the $\mathrm{H}_{2}$ consumption $/ \mathrm{H}_{2} \mathrm{O}$ formation starts between $100 \mathrm{~K}$ (Dagaut et al.) and $50 \mathrm{~K}$ (model presented in this study and model from Klippenstein et al.) before the experimental profile. Note that the model from Klippenstein et al. is even more reactive than the two other models above $850 \mathrm{~K}$. Concerning the $\mathrm{NO}$ and $\mathrm{NO}_{2}$ profiles (Fig. 14f), the model from Dagaut et al. is still significantly over-reactive for these species, whereas the model presented in this study and the model from Klippenstein et al. are within an acceptable level of agreement with the data, the latest one being slightly closer to the experimental data. 

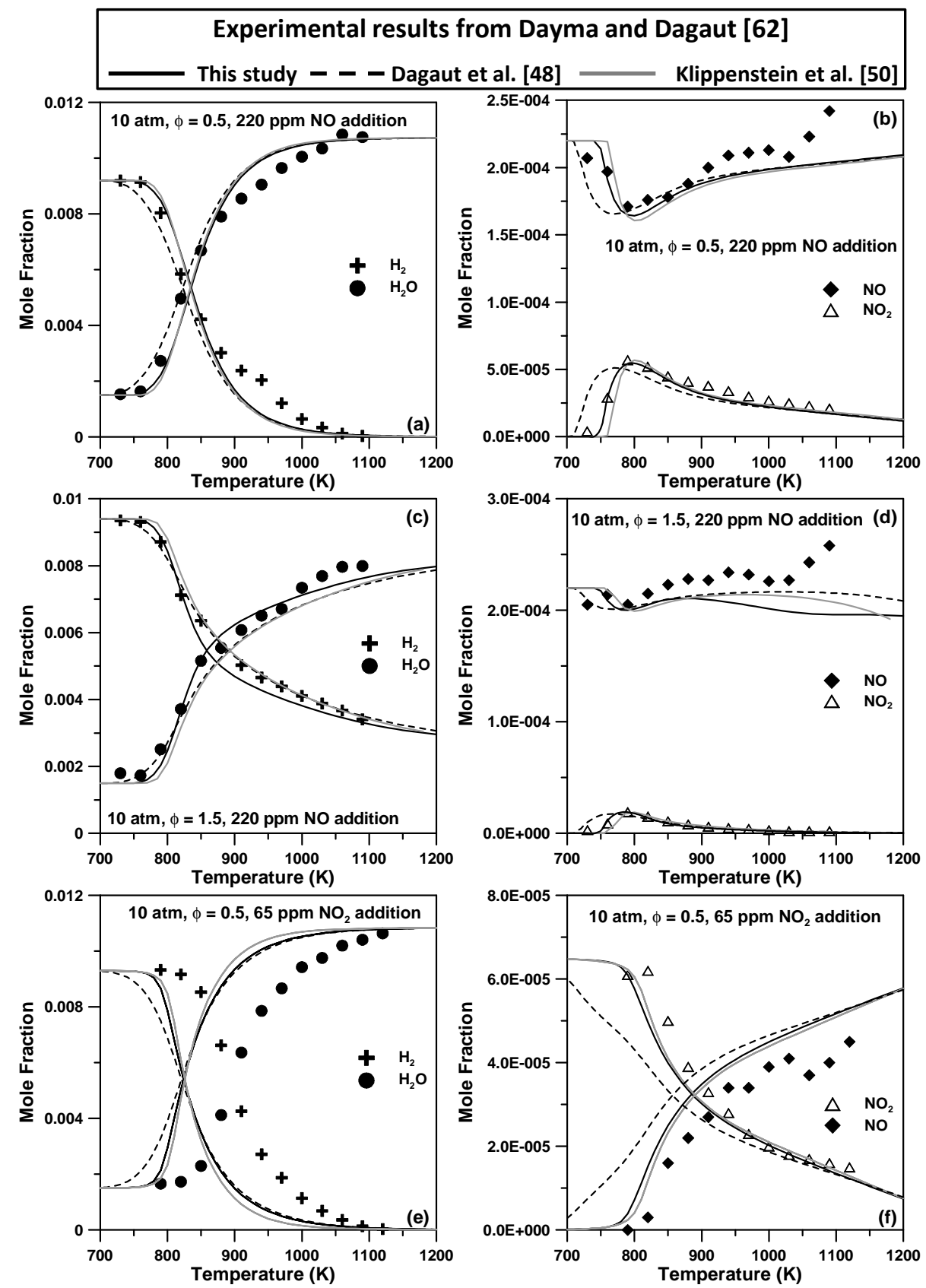

Figure 14: Comparison between models and jet stirred reactor experiments from Dayma and Dagaut [62] of $\mathrm{H}_{2} / \mathrm{O}_{2}$ mixtures with $\mathrm{NO}$ or $\mathrm{NO}_{2}$ addition.

\section{HCN sub-mechanism validation}

As mentioned by Dagaut et al. [48], $\mathrm{HCN}$ and $\mathrm{NH}_{3}$ are intermediately formed during the combustion of coal and biomass fuels which contain N-bounded structures, and most of the HCN released subsequently forms NOx. It was therefore important to verify that the HCN chemistry developed in Dagaut et al. [48] was not altered by the changes made to the larger model in this study. The ignition delay times of a $0.01 \mathrm{HCN} / 0.01 \mathrm{O}_{2}$ mixture diluted in Ar was determined at $10 \%$ of the peak value of the $\mathrm{OH}$ profile by Higashihara et al. [63]. The comparison between these data and the 
model of Dagaut et al. and the modified model proposed in this study (note that the mechanism of Klippenstein et al. does not contain HCN and related species) is visible in Fig. 15. As can be seen in this figure, the original mechanism of Dagaut et al. is significantly over-reactive, a factor around 1.5 being observed compared to the experimental data. The modified model from this study predicts ignition delay times that are slightly longer and in a better agreement with the data, although the difference between the two models is slim, and both are similarly over-reactive.

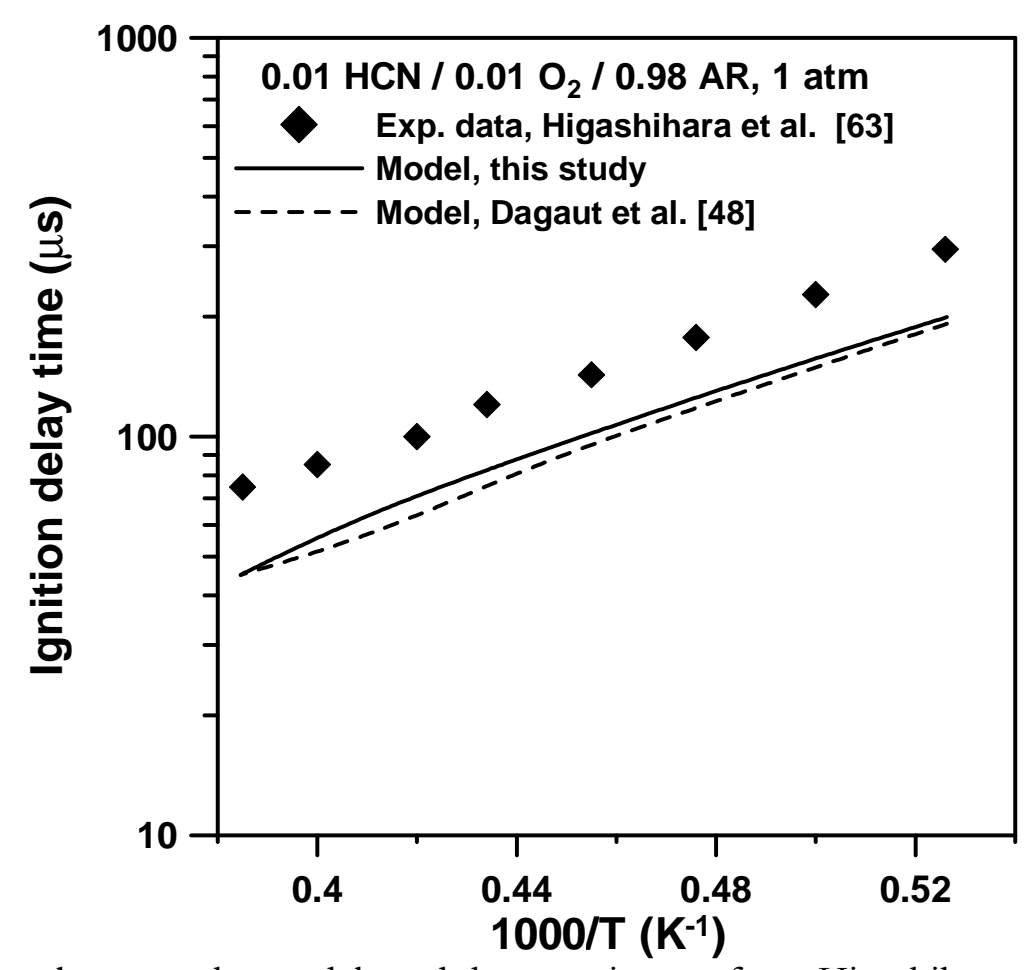

Figure 15: Comparison between the models and the experiments from Higashihara et al. [63] for the ignition delay times of a $0.01 \mathrm{HCN} / 0.01 \mathrm{O}_{2}$ mixture diluted in Ar. The ignition delay times were determined at $10 \%$ of the peak value of the $\mathrm{OH}$ profile

Thielen and Roth [64] followed N, O, and $\mathrm{H}$ temporal profiles using highly diluted mixtures of $\mathrm{HCN}$ and $\mathrm{O}_{2}$ in a shock tube. As can be seen in Fig. 16, the beginning of the rise in the $\mathrm{N}$ profile is well captured by the models, the two models almost yielding the same results, but the maximum value of the $\mathrm{N}$ profile is over-estimated. The model modified in the present study predicts levels of the $\mathrm{N}$ radical that are higher than the original mechanism from Dagaut et al. [48], although both versions similarly overpredict the peak $\mathrm{N}$-atom mole fraction. Note that the decrease of the $\mathrm{N}$ radical after $600 \mu \mathrm{s}$ for the hightemperature case (Fig. 16b) is well predicted by the two models. 


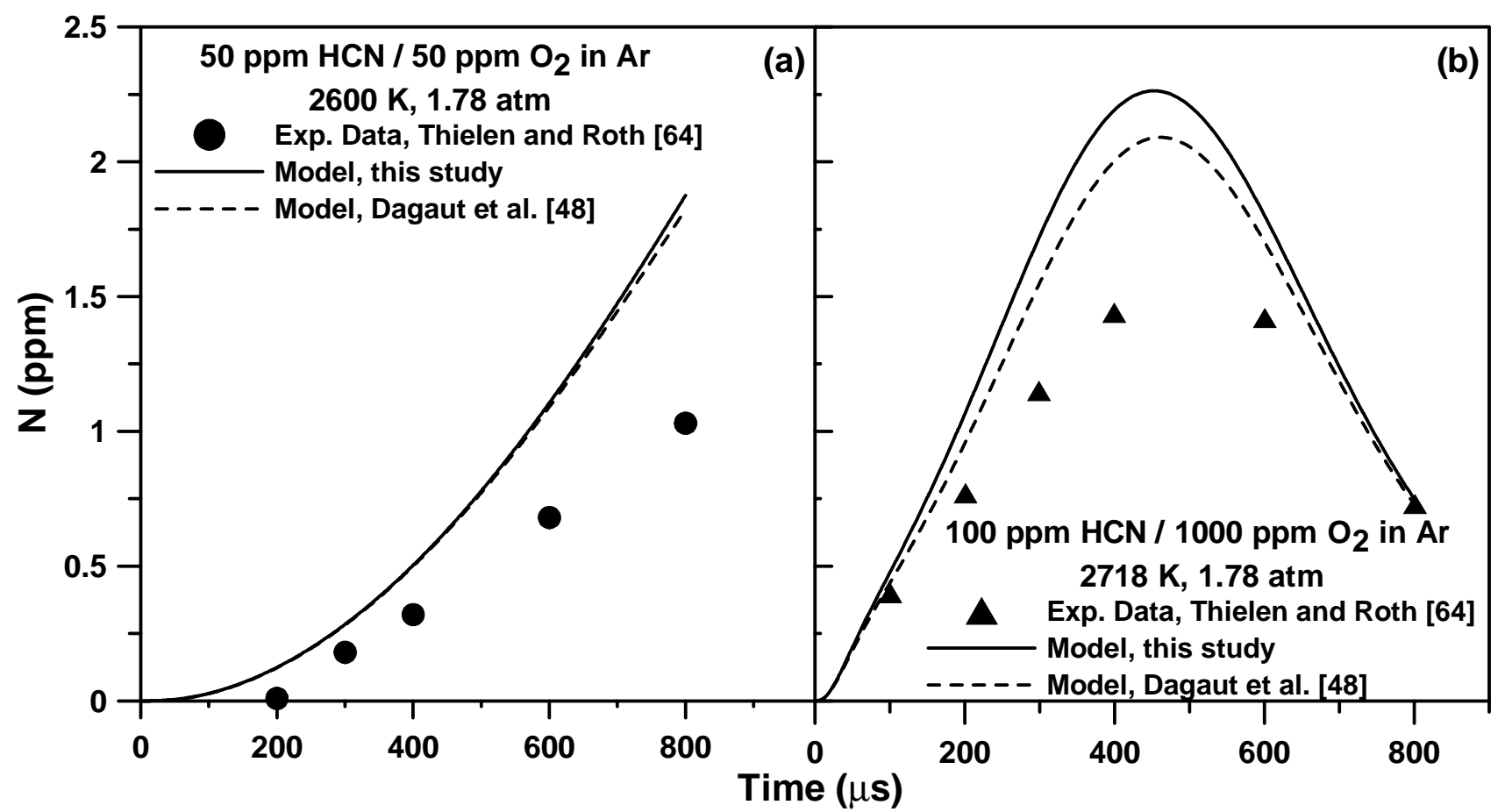

Figure 16: Comparison between the models and the experiments for $\mathrm{N}$ mole fraction traces behind reflected shock waves for $\mathrm{HCN} / \mathrm{O}_{2}$ mixtures highly diluted in Ar at (a) 2600 and (b) $2718 \mathrm{~K}$ by Thielen and Roth [64].

The radical O profile from Thielen and Roth [67] is visible in Fig. 17. As can be seen, the agreement between both models and the data is good during the first $500 \mu \mathrm{s}$. For longer test times, the models tend to under-predict the quantity of $\mathrm{O}$ present in the reactive mixture. The model proposed in the present study deviates slightly from the original model after $400 \mu$ s and predicts a maximum amount of $\mathrm{O}$ radical that is about $0.5 \mathrm{ppm}$ lower than the model of Dagaut et al. [48]. 


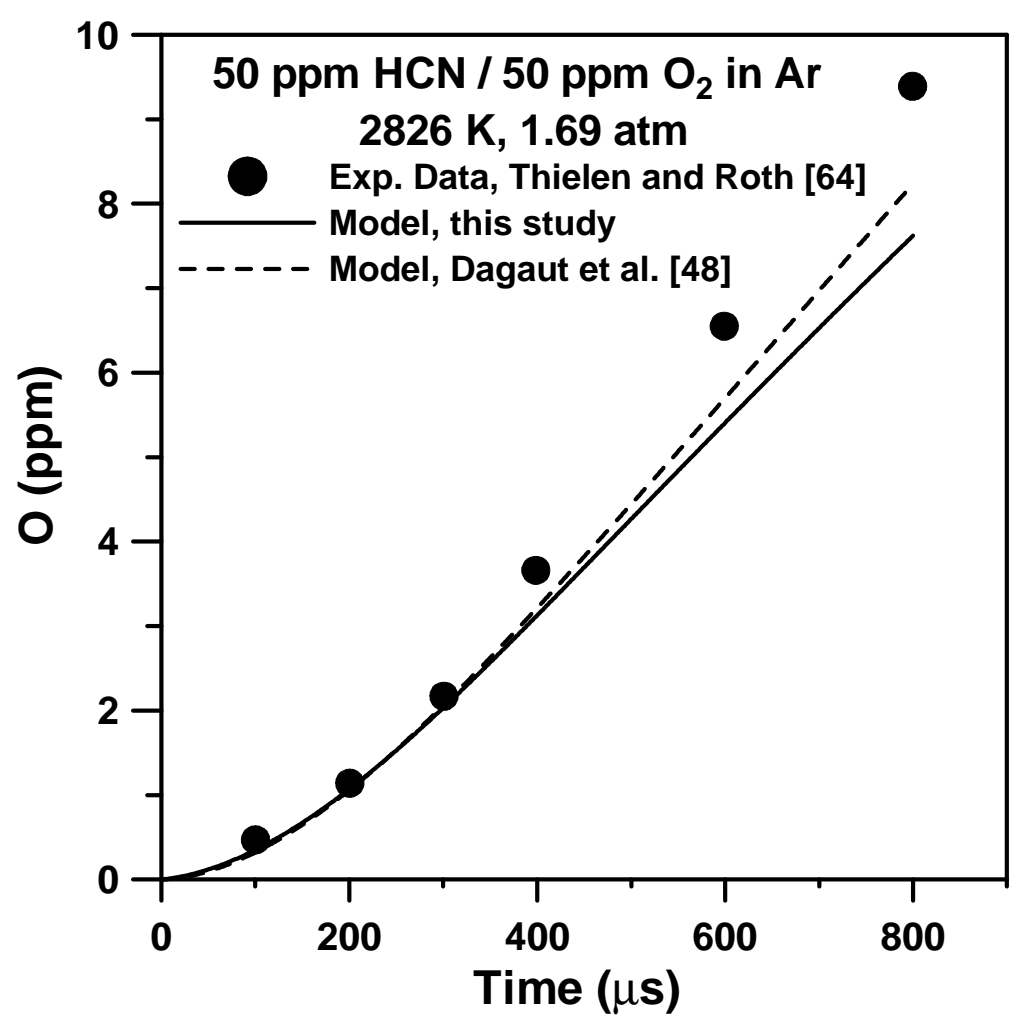

Figure 17: Comparison between the models and the experiment for an $\mathrm{O}$ absorption trace behind reflected shock waves for a 50-ppm HCN/50-ppm $\mathrm{O}_{2}$ mixture in $\mathrm{Ar}$ at $2826 \mathrm{~K}$ and 1.69 atm by Thielen and Roth [64].

Figure 18 shows the comparison between the experiments from Thielen and Roth [64] and the models for the $\mathrm{H}$ radical. As can be seen, the experimental trend is well captured by the models, but the $\mathrm{H}$ concentration is significantly over-predicted by both after $400 \mu \mathrm{s}$. As for the $\mathrm{N}$ profiles, the model proposed in the present study predicts higher concentrations than the original model from Dagaut et al. [48]. 


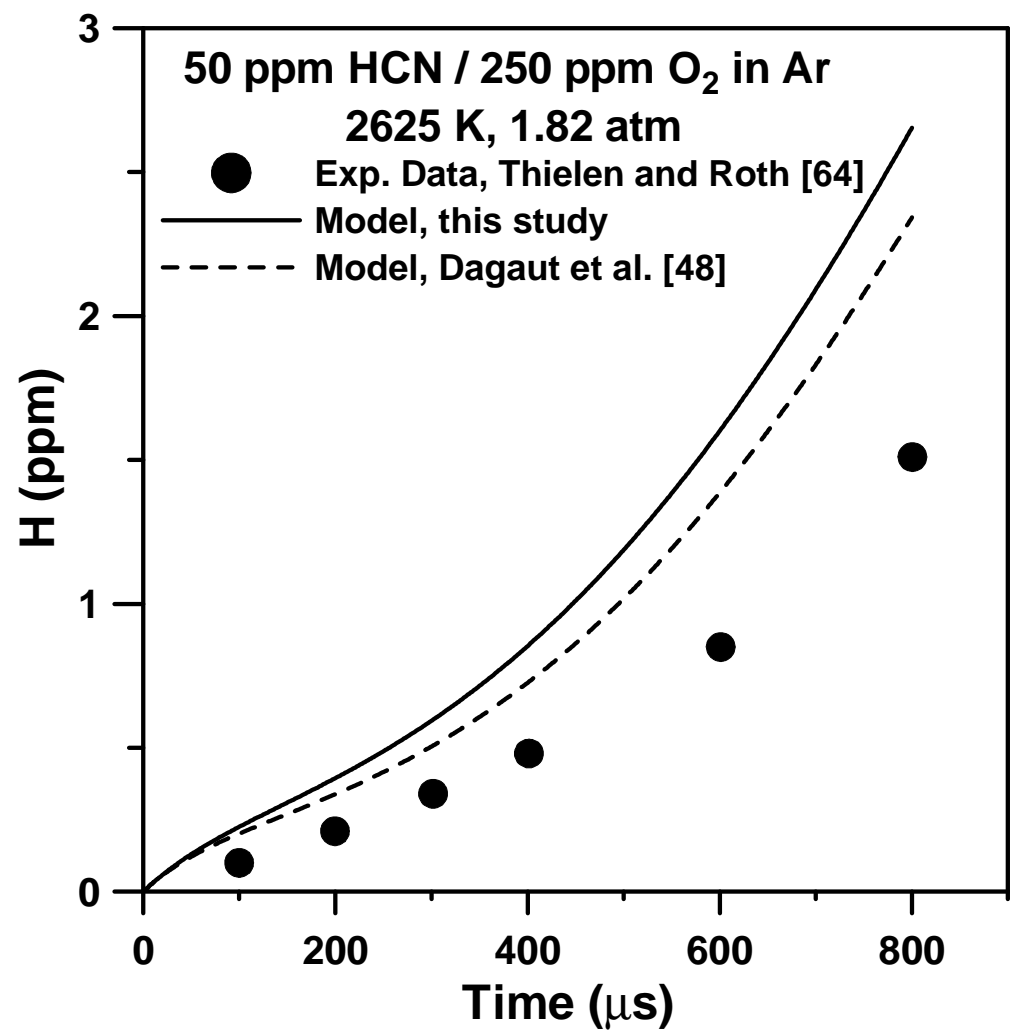

Figure 18: Comparison between the models and the experiment for $\mathrm{H}$-atom mole fraction behind reflected shock waves for a 50-ppm HCN/250-ppm $\mathrm{O}_{2}$ mixture diluted in Ar at $2625 \mathrm{~K}$ and 1.82 atm by Thielen and Roth [64].

\section{$\mathrm{NH}_{3}$ sub-mechanism validation}

Predictions against $\mathrm{NH}_{3}$ data from this study for the model proposed herein and for the two other reference models are visible in Fig. 4. As can be seen in this figure, the model from Klippenstein et al. [50] is consistently over-reactive. The disagreement with the data can reach a factor 2 to 3 , although a smaller difference is generally observed. The ignition delay times at higher pressure (around $30 \mathrm{~atm}$ ) are however well predicted at low temperatures for the stoichiometric and fuel-lean conditions. The models from Dagaut et al. [48] and from the present study (which is based on the model of Dagaut et al. [48]) are very close to each other and provide good predictions over the entire range of conditions investigated. The model proposed in this study is slightly more reactive than the model of Dagaut et al., which modestly improves the predictions in some cases $(\phi=0.5$ at all pressure conditions, low-pressure data for the other equivalence ratios) but also slightly deteriorates them for certain cases (30-atm data at $\phi=1$, for example). However, the two models can be viewed as good models to predict these kind of ammonia oxidation data.

The $\mathrm{NH}$ and $\mathrm{NH}_{2}$ profiles from Davidson et al. [37] are useful for validating the pyrolysis chemistry of a $\mathrm{NH}_{3}$ model since these authors passivated the wall of their shock tube prior to conducting their experiments. Figure 19 shows temporal NH profiles (19a) and maximum $\mathrm{NH}$ level for several $\mathrm{NH}_{3}$ concentrations at various temperatures. As can be seen from Fig. 19a, the predictions of model from Dagaut et al. [48] have been significantly improved by the modifications made in the present study. The amount of $\mathrm{NH}$ predicted is much lower and closer to the experimental data for the two temperatures. This improvement was made by using the reaction rate coefficient used in Miller and Bowman [5] for 
the reaction $\mathrm{NH}+\mathrm{H} \leftrightarrows \mathrm{N}+\mathrm{H}_{2}$. The rate of this new reaction is higher by a factor of 3 , which allows direct reduction of the $\mathrm{NH}$ concentration as well as of the $\mathrm{NH}_{2}$ concentration, to some extent, by shifting the equilibrium. For the highest temperature of $2652 \mathrm{~K}$, the model of Klippenstein et al. [50] predicts a maximum level of $\mathrm{NH}$ that is a bit higher than the level predicted by the model from this study and the experimental level. However, the decay in the NH signal is better reproduced by the model of Klippenstein et al. For the lower temperature investigated, $2294 \mathrm{~K}$, the model of Klippenstein et al. is however in better agreement with the data for the maximum of NH predicted. This behavior is similar for other temperatures and $\mathrm{NH}_{3}$ concentrations, as visible in Fig. 19b. Overall, the model from the present study follows the experimental trend better than the other models, especially compared to the model from Klippenstein et al. which is in close agreement with the data for the lowest temperatures but rapidly deviates from the experimental profile as the temperature increases. The model from the present study predicts well the data at an initial $\mathrm{NH}_{3}$ mole fraction of 0.001 but tends to over-predict the amount of $\mathrm{NH}$ formed for higher $\mathrm{NH}_{3}$ concentrations.
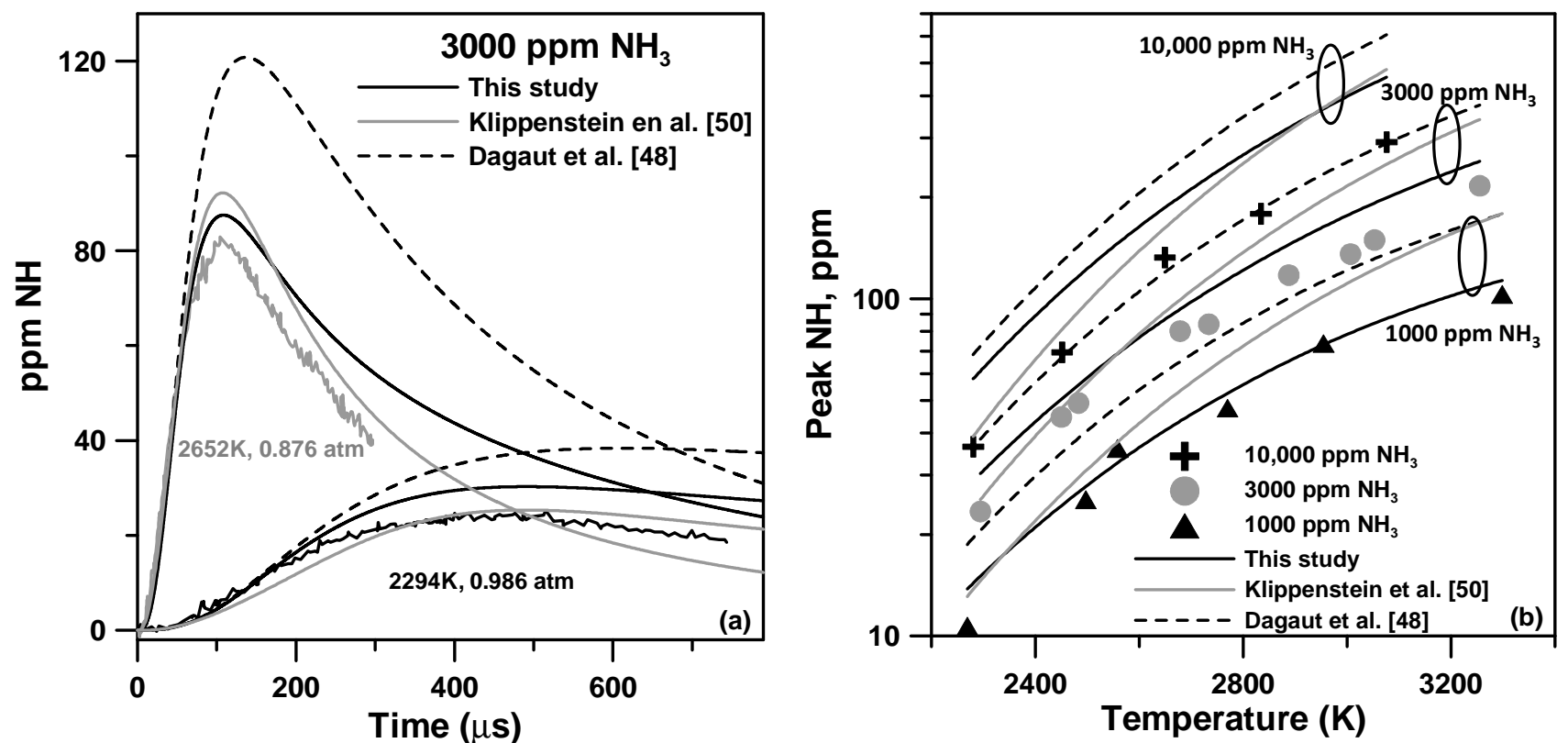

Figure 19: Comparison between the models and the experiments from Davidson et al. [37] for (a) $\mathrm{NH}$ profiles, and (b) maximum $\mathrm{NH}$ level for the pyrolysis of diluted mixtures of $\mathrm{NH}_{3}$ in $\mathrm{Ar}$.

Similar results are available with $\mathrm{NH}_{2}$ as can be seen in Fig. 20. Profiles for $\mathrm{NH}_{2}$ (Fig. 20a) are noticeably under-predicted by the mechanism of Klippenstein et al. [50], whereas predictions from the mechanisms of Dagaut et al. [48] and from the present study are close to each other and in relatively good agreement with the data. The maximum $\mathrm{NH}_{2}$ concentration is well predicted by these two mechanisms over a wide range of temperatures, as can be seen in Fig. $20 \mathrm{~b}$. 

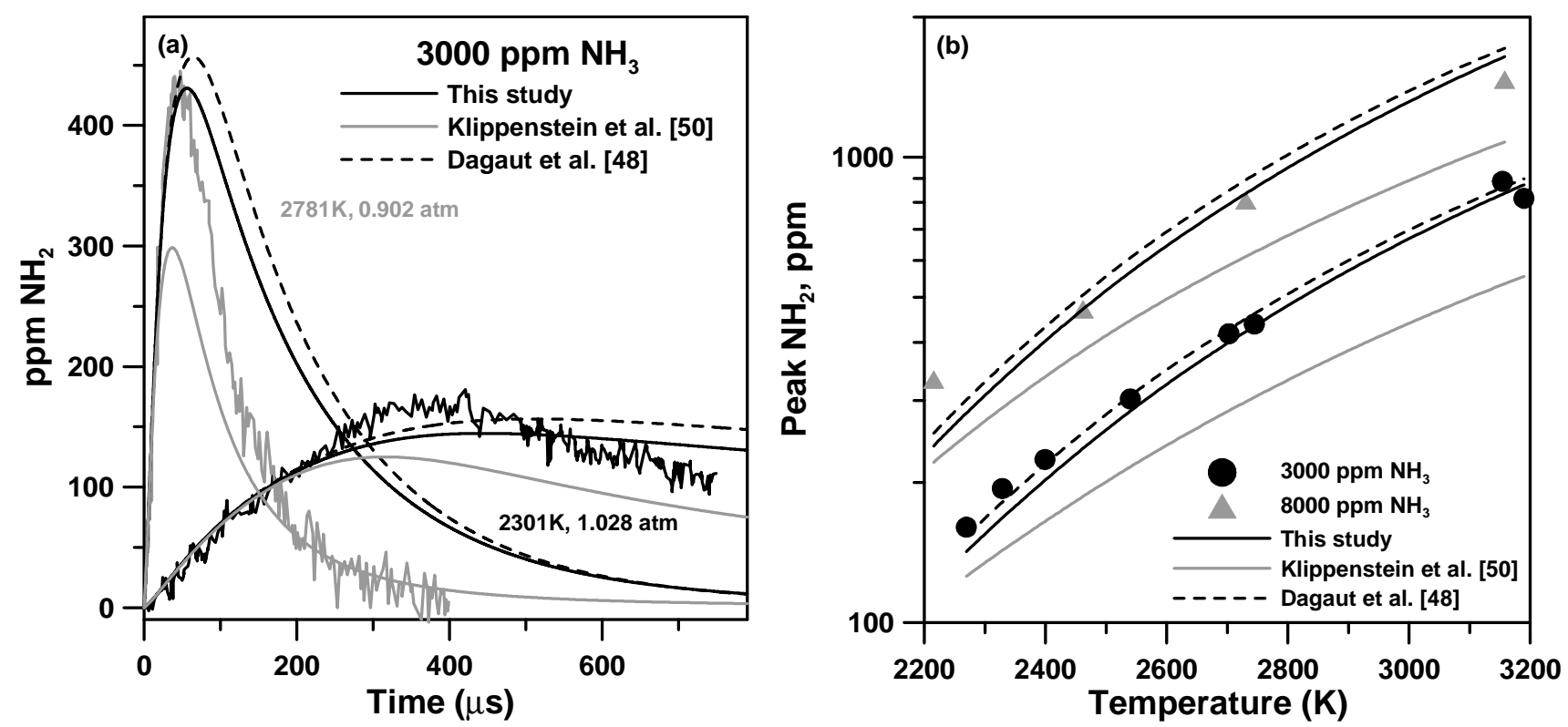

Figure 20: Comparison between the models and the experiments from Davidson et al. [37] for (a) $\mathrm{NH}_{2}$ profiles, and (b) maximum $\mathrm{NH}_{2}$ level for the pyrolysis of diluted mixtures of $\mathrm{NH}_{3}$ in $\mathrm{Ar}$ at various temperatures.

Finally, the shock-tube data from Drummond [57] were selected to validate the model as $\mathrm{N}_{2} \mathrm{O}$ was used as an oxidant instead of $\mathrm{O}_{2}$, hence validating both $\mathrm{N}_{2} \mathrm{O}$ and $\mathrm{NH}_{3}$ sub-mechanisms at the same time. Although it is not reported that the surface was passivated with $\mathrm{NH}_{3}$ prior to taking those measurements, the relatively high concentration of $\mathrm{NH}_{3}$ in the mixture (4\% vol.) should prevent there being too large of a decrease in the initial $\mathrm{NH}_{3}$ concentration. The modeling pressure was taken at 3.9 atm (the experimental data are reported to be between 3.3 and $4.4 \mathrm{~atm}$ ) and, as can be seen in Fig. 21, all the mechanisms are in close agreement with the data, although the predicted activation energy is a bit too low. 


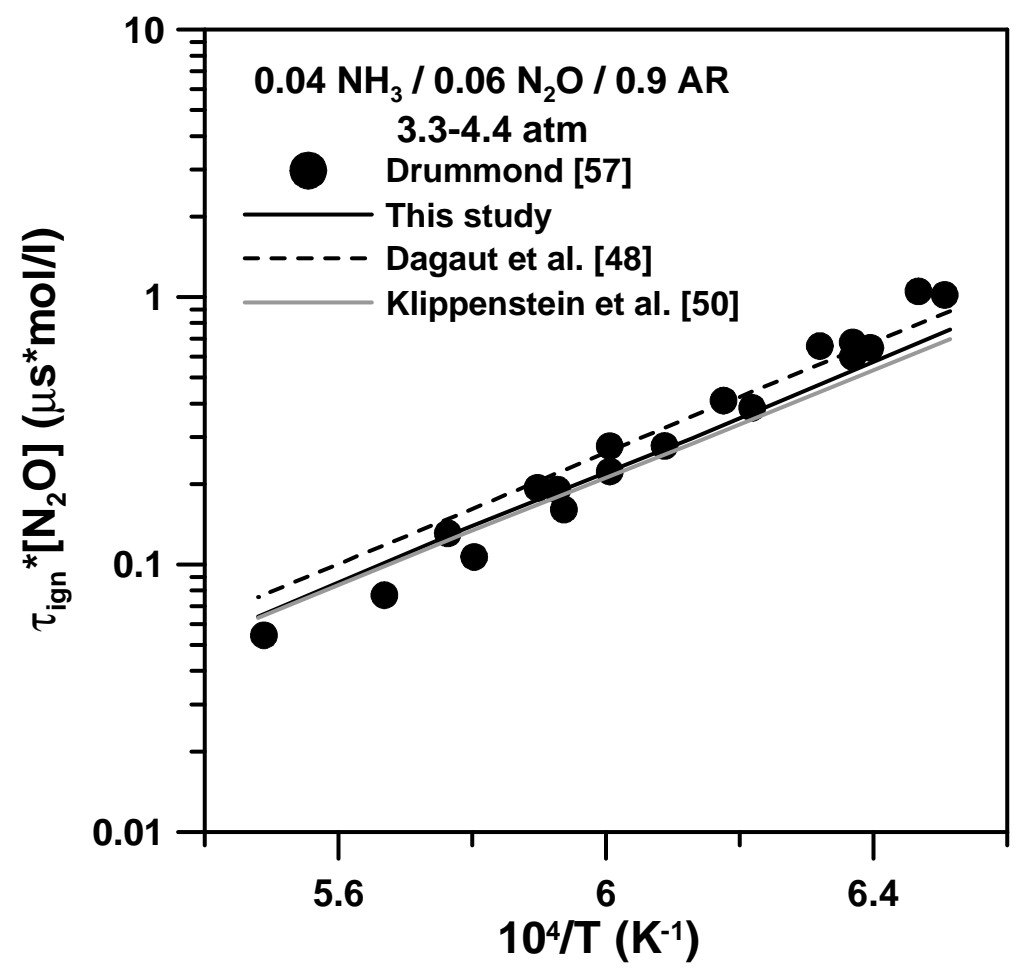

Figure 21: Comparison between models and experiments from Drummond [57] for the ignition delay times of a $0.04 \mathrm{NH}_{3} / 0.06 \mathrm{~N}_{2} \mathrm{O}$ mixture diluted in Ar.

To further validate the mechanism, laminar flame speed data with ammonia would have been valuable. It is worth mentioning that although the burning velocity of ammonia-containing mixtures was measured in a few studies in the past [72-74], none of these measurements can be considered as accurate due to the lack of corrections of the burning velocity, namely for the effects of flame stretch [20]. It can therefore be concluded that new, accurate measurements for the burning velocity of ammonia are needed.

\section{Sensitivity analysis}

To further exhibit the difference between the models and to identify important reactions for $\mathrm{NH}_{3}$ oxidation, a sensitivity analysis on the $\mathrm{OH}^{*}$ radical was performed for the experiments with 99\% $\mathrm{Ar}$ dilution. It has been shown in previous studies by the authors that $\mathrm{OH}^{*}$ sensitivity analyses tend to produce results that are very similar to those obtained from sensitivity analyses performed with respect to the ignition delay time [61]. Hence, the important reactions from the $\mathrm{OH}^{*}$ sensitivity analysis can be assumed to be the important reactions for the ignition process. Figure 22 shows the normalized results of this sensitivity analysis for some selected conditions: $\phi=0.5,1.4 \mathrm{~atm}$, and $2000 \mathrm{~K}$, where a noticeable difference can be observed between the models in terms of ignition delay time; $\phi=1.0,30 \mathrm{~atm}$, and $1580 \mathrm{~K}$, where the three models yield very similar results; and $\phi=2.0,11 \mathrm{~atm}$, and $2000 \mathrm{~K}$, where the mechanism proposed in this study and the mechanism of Dagaut et al. [48] are close to each other (the mechanism from Klippensteim et al. [50] being more reactive at these conditions).

For the fuel-lean, lower-pressure condition (Fig. 22a-c), the sensitivity analysis shows that the two most-promoting reactions $\left(\mathrm{NH}_{3}+\mathrm{M} \leftrightarrows \mathrm{NH}_{2}+\mathrm{H}+\mathrm{M}(\mathrm{r} 1)\right.$ and $\left.\mathrm{H}+\mathrm{O}_{2} \leftrightarrows \mathrm{OH}+\mathrm{O}(\mathrm{r} 2)\right)$ and the mostinhibiting reaction $\left(\mathrm{NH}_{3}+\mathrm{H} \leftrightarrows \mathrm{NH}_{2}+\mathrm{H}_{2}(\mathrm{r} 3)\right)$ are the same for all 3 models. Differences between the 
model from Dagaut et al. and the modified version proposed in this study are not large overall. Overall, most of the reactions are the same and rank similarly in terms of relative sensitivity. One noticeable difference is that the most-sensitive reaction $\mathrm{NH}_{3}+\mathrm{M} \leftrightarrows \mathrm{NH}_{2}+\mathrm{H}+\mathrm{M}(\mathrm{r} 1)$ has a more-prominent role in the modified mechanism, the other reactions being normalized to this one. Apart from the three aforementioned reactions, several differences are visible between the model from Klippenstein et al. and the model proposed in the present study, with the role of the $\mathrm{N}_{2} \mathrm{H}_{2}$ species being very important in the mechanism of Klippenstein et al. The sensitivity study using the mechanisms showed that the $\mathrm{N}_{2} \mathrm{Hx}$ $\left(\mathrm{N}_{2} \mathrm{Hx}=\mathrm{N}_{2} \mathrm{H}_{2}, \mathrm{~N}_{2} \mathrm{H}_{3}\right.$, and $\left.\mathrm{N}_{2} \mathrm{H}_{4}\right)$ chemistry in the model of Klippenstein et al. has a great role in the discrepancy between the results of this model and the data from this study.

For the stoichiometric case at $30 \mathrm{~atm}$, Fig. 22d-f, where the models yield similar results at low temperature (see Fig. 4b), the sensitivity analysis exhibits many differences between the models. The comparison of the results for the model proposed in this study and the model of Dagaut et al. shows that the most-sensitive (promoting and inhibiting) reactions are the same between these two models. However, due to the modifications made during this study, their relative sensitivities (and order relative to the most-sensitive reactions) are different. As for the previous condition, the sensitivity of the reaction $\mathrm{H}+\mathrm{O}_{2} \leftrightarrows \mathrm{OH}+\mathrm{O}(\mathrm{r} 2)$ is reduced in the modified mechanism compared to the reaction (r1) and $\mathrm{NH}+\mathrm{O}_{2} \leftrightarrows \mathrm{HNO}+\mathrm{O}(\mathrm{r} 4)$ (third most-sensitive reaction, but with a high sensitivity coefficient (most sensitive reaction in Dagaut et al. [48])). It is also interesting to note that the reaction $\mathrm{N}_{2} \mathrm{O}(+\mathrm{M}) \leftrightarrows$ $\mathrm{N}_{2}+\mathrm{O}(+\mathrm{M})(\mathrm{r} 5)$ appears in the 10 most-sensitive reactions of the modified mechanism, for all condition in Fig. 22. It therefore stresses the importance of the $\mathrm{N}_{2} \mathrm{O}$ sub-mechanism in the ignition chemistry during ammonia oxidation. Once again, most of the sensitive reactions are the same between the mechanism of Klippenstein et al. and the model proposed in this study. In addition to the presence of a reaction involving $\mathrm{N}_{2} \mathrm{H}_{2}$, one can notice the presence of the inhibiting reaction $\mathrm{H}+\mathrm{O}_{2}+\mathrm{M} \leftrightarrows \mathrm{HO}_{2}+\mathrm{M}$ (r6), the latest one being not observed with the other models, including with the model proposed in this study with the updated $\mathrm{H}_{2} / \mathrm{O}_{2}$ chemistry from Kéromnès et al. [65].

For the fuel-rich condition at $10 \mathrm{~atm}$, Fig. 22g-i, the sensitivity analysis shows that the differences between the model of Dagaut et al. and the model proposed in this study are rather slim. In fact, 8 out of 10 reactions are the same or nearly on the same order in terms of normalized sensitivities. The results of this sensitivity analysis hence confirm that the modifications to the model of Dagaut et al. are not very important in regards to the $\mathrm{NH}_{3}$ chemistry, although predictions were improved for most of the other NOx data, as shown above. At this fuel-rich condition, the difference between the model proposed in the present study and the model of Klippenstein et al. are relatively important. Although the most-sensitive reactions are the same, it is worth mentioning that most of the promoting reactions with an intermediate sensitivity are different. In the case of the model of Klippenstein et al., those intermediate-sensitivity reactions are pyrolysis reactions (i.e. without involvement of either oxygen molecules or atoms) that involve $\mathrm{NH}_{2}$ or $\mathrm{N}_{2} \mathrm{H}_{2}$. This importance of these species illustrates some potentially important differences in the treatment of the $\mathrm{NH}_{3}$ oxidation between the models and helps explain the difference in terms of predictions for the new ignition delay time measurements presented in this study. 


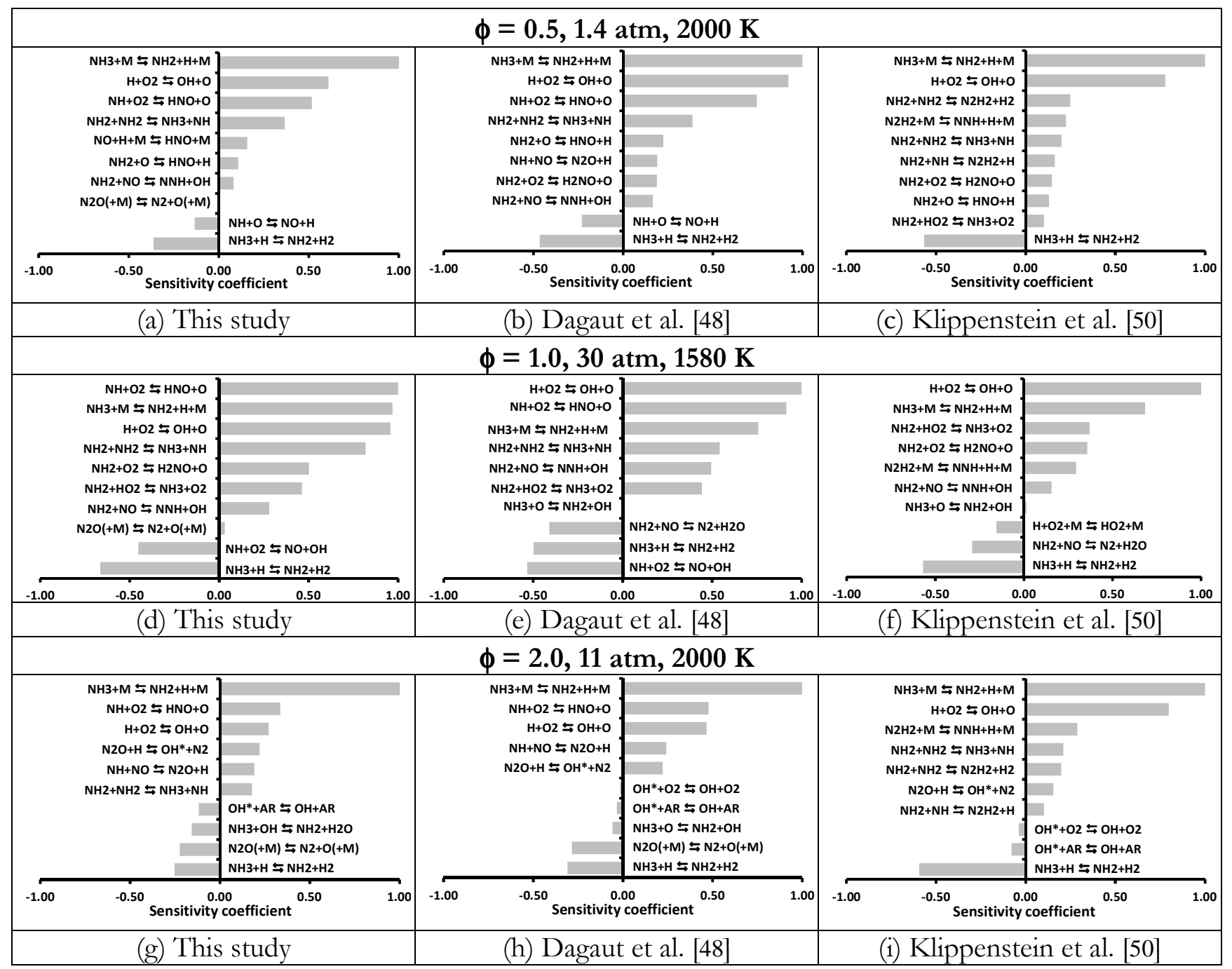

Figure 22: Normalized sensitivity analysis on $\mathrm{OH}^{*}$ for some selected conditions at $99 \%$ Ar dilution with the mechanism proposed in this study ((a), (d), and (g)), the mechanism from Dagaut et al. [48] ((b), (e), and (h)), and the mechanism from Klippenstein et al. [50] ((c), (f), and (i)).

\section{Conclusions}

It is important to understand the details of $\mathrm{NH}_{3}$ combustion chemistry for practical reasons such as the control of NOx formation or for NOx removal processes. To date, several shock-tube studies have been performed over the past few decades, and several detailed kinetics mechanisms are available from the literature. Unfortunately, experimental conditions are not accurately reported in the shock-tube literature, and large discrepancies are observed amongst the models compared herein, making the selection of a good core model to predict $\mathrm{NH}_{3}$ combustion difficult. Thus, new and reliable ignition delay time measurements were obtained over a wide range of conditions (around 1.4, 11, and $30 \mathrm{~atm}$, between 1560 and $2490 \mathrm{~K}$, and for equivalence ratios 0.5, 1.0, and 2.0). Results showed that both the equivalence ratio and the pressure had important effects on the ignition delay time of ammonia.

Models from the literature were then compared to this new set of data, and it was found that only the model from Dagaut et al. [48] provided satisfactory results (when the reaction $\mathrm{N}_{2} \mathrm{O}+\mathrm{H} \leftrightarrows \mathrm{N}_{2}+$ 
$\mathrm{OH}^{*}$ from Hidaka et al. [59] was added with the $\mathrm{OH}^{*}$ mechanism from Hall and Petersen [55]). This mechanism was further improved using sub-mechanisms and reactions available in the literature, and the final $\mathrm{NOx}$ mechanism is able to predict selected $\mathrm{NH}_{3} / \mathrm{HCN} / \mathrm{NO}\left({ }_{2}\right)$ and $\mathrm{N}_{2} \mathrm{O}$ data with good accuracy over a range of conditions and types of experiment. The sensitivity analysis showed that the differences between the initial model of Dagaut et al. and the model proposed in this study are rather slim for $\mathrm{NH}_{3}$ oxidation, although significant improvements were made on the modeling of $\mathrm{NOx} / \mathrm{N}_{2} \mathrm{O}$ data. Some noticeable differences were however observed between the most-recent literature model from Klippenstein et al. [50] and the final model of the present study, notably for fuel-rich conditions where pyrolysis reactions involving $\mathrm{NH}_{2}$ and $\mathrm{N}_{2} \mathrm{H}_{2}$ have a greater role in the most-recent mechanism.

\section{Acknowledgments}

This material is based upon the work supported by two UTSR grants from the Department of Energy, NETL, under Award Numbers DE-FE0004679 and DE-FE0011778.

\section{References}

[1] S. Sukumaran, S.-C. Kong. Combust. Flame 160 (2013) 2159-2168.

[2] D. Xu, D. R. Tree, R. S. Lewis. Biomass and Bioenergy 35 (2011), 2690-2696.

[3] T. Mendiara, P. Glarborg. Combust. Flame 156 (2009), 1937-1949.

[4] K. Kohse-Höinhaus, D.F. Davidson, A.Y. Chang, R.K. Hanson. J. Quantitative Spectroscopy and Radiative Transfer 42 (1989), 1-17.

[5] J.A. Miller, C.T. Bowman. Prog. Energy Combust. Sci. 15 (1989), 287-338.

[6] P. Glarborg, A.D. Jensen, J.E. Johnson. Prog. Energy Combust. Sci. 29 (2003), 89-113.

[7] S. Salimian, R.K. Hanson, C.H. Kruger. Combust. Flame 56 (1984), 83-95.

[8] J.A. Miller, P. Glarborg. Int. J. Chem. Kinet. 31 (1999), 757-765.

[9] C.C. Schmidt, C.T. Bowman. Combust. Flame 127 (2001), 1958-1970.

[10] J.A. Miller, M.J. Pilling, J. Troe. Proc. Combust. Inst. 30 (2005), 43-88.

[11] D.T. Pratt, E.S. Starkman. Proceed. Combust. Instit. 12 (1969), 891-899.

[12] C. Duynslaegher, F. Contino, J. Vandooren, H. Jeanmart. Combust. Flame 159 (2012), 2799-2805.

[13] L. Cohen. Fuel 34 (1955), 123-127.

[14] C.P. Fenimore, G. W. Jones, J. Phys. Chem. 65 (1961), 298-303.

[15] D.I. MacLean, H.Gg. Wagner. Proc. Combust. Inst. 11 (1967), 871-878.

[16] V. Zakaznov, L. Kursheva. Zhurnal Prikladnoi Khimii 53 (1980), 1865-1867.

[17] C.J. Dasch, R.J. Blint. Combust. Sci. Technol. 41 (1984), 223-244.

[18] A.M. Dean, M.-S. Chou, D. Stern. Int. J. Chem. Kinet. 16 (1984), 633-653.

[19] J. Bian, J. Vandooren, P.J. van Tiggelen, Proc. Combust. Inst. 21 (1986), 953-963.

[20] M. Brown, D. Smith. Proceed. Combust. Instit. 25 (1994), 1011-1018.

[21] C. Duynslaegher, H. Jeanmart, J. Vandooren. Proceed. Combust. Instit. 32 (2009), 1277-1284.

[22] T. Takeyama, H. Miyama. J. Chem. Phys. 42 (1965), 3737-3738.

[23] T. Takeyama, H. Miyama. Bull. Chemical Society Japan 38 (1965), 1670-1674.

[24] T. Takeyama, H. Miyama. Bull. Chemical Society Japan 39 (1966), 2352-2355.

[25] T. Takeyama, H. Miyama. Bull. Chemical Society Japan 39 (1966), 2609-2612.

[26] T. Takeyama, H. Miyama. Proced. Combust. Instit. 11 (1967), 845-852.

[27] H. Miyama, R. Endoh. Combust. Flame 11 (1967), 359-360.

[28] H. Miyama, R. Endoh. J. Chem. Phys. 46 (1967), 2011-2012.

[29] D.C. Bull. Combust Flame 12 (1968), 603-610. 
[30] H. Miyama. Bull. Chemical Society Japan 41 (1968), 1761-1765.

[31] H. Miyama. J. Chem. Phys. 48 (1968), 1421-1422.

[32] J.N. Bradley, R. N. Butlin, D. Lewis. Trans. Faraday Soc. 64 (1968), 71-78.

[33] L.J. Drummond. Combust. Sci. Technol. 5 (1972), 175-182.

[34] N. Fujii, H. Miyama, M. Koshii, T. Asaba. Proceed Combust. Instit. 18 (1981), 873-883.

[35] S. Salimian, R.K. Hanson, C.H. Kruger. Combust. Flame 56 (1984), 83-95.

[36] S. Salimian, R.K. Hanson, C.H. Kruger. Int. J. Chem. Kin. 16 (1984), 725-739.

[37] D.F. Davidson, K. Kohse-Hoinghaus, A.Y. Chang, R.K. Hanson. Int. J. Chem. Kin. 22 (1990), 513-535.

[38] A.M. Dean, J.E. Hardy, R.K. Lyon. Proc. Combust. Inst. 19 (1982), 97-105.

[39] T. Hulgaard, K. Dam-Johansen. AIChE J. 39 (1993), 1342-1354.

[40] T. Hasegawa, M. Sato. Combust. Flame 114 (1998), 246-258.

[41] V. J. Wargadalam, G. Löffler, F. Winter, H. Hofbauer. Combust. Flame 120 (2000), 465-478.

[42] A. Konnov, J. De Ruyck. Combust. Sci. Technol. 168 (2001), 1-46.

[43] Ø. Skreiberg, P. Kilpinen, P. Glarborg. Combust. Flame 136 (2004) 501-518.

[44] J. Bian, J. Vandooren, P. van Tiggelen. Proc. Combust. Inst. 23 (1990) 379-386.

[45] M.A. Mueller, R. Yetter, F. Dryer. Int. J. Chemical Kinet. 32 (2000), 317-339.

[46] K.J. Hughes, A.S. Tomlin, E. Hampartsoumian, W. Nimmo, I.G. Zsély, M. Ujvári, T. Turányi, A.R. Clague, M.J. Pilling. Combust. Flame 124 (2001), 573-589.

[47] P. Dagaut, A. Nicolle. Proc. Combust. Inst 30 (2005), 1211-1218.

[48] P. Dagaut, P. Glarborg, M.U. Alzueta. Prog. Energy Combust. Sci. 34 (2008), 1-46.

[49] R. Mével, S. Javoy, F. Lafosse, N. Chaumeix, G. Dupré, C.-E. Paillard. Proceed. Combust. Inst. 32 (2009), 359-366.

[50] S.J. Klippenstein, L. B. Harding, P. Glarborg, J.A. Miller. Combust. Flame 158 (2011), 774-789.

[51] T. Mendiara, P. Glarborg. Combustion and Flame 156 (2009), 1937-1949.

[52] C.J. Aul, W.K. Metcalfe, S.M. Burke, H.J. Curran, E.L. Petersen. Combustion and Flame 160

(2013), 1153-1167.

[53] E.L. Petersen, M. J. A. Rickard, M. W. Crofton, E. D. Abbey, M. J. Traum, D. M. Kalitan. Meas.

Sci. Technol. 16 (2005), 1716-1729.

[54] T.R. Roose, R.K. Hanson, C.H. Kruger. Proceed. Combust. Instit. 18 (1981), 854-862.

[55] J.M. Hall, E.L. Petersen. Int. J. Chem. Kinet. 38 (2006), 714-724.

[56] Y. Hidaka, H. Takuma, M. Suga. J. Phys. Chem. 89 (1985), 4903-4905.

[57] L. Drummond. Aust. J. Chem. 20 (1967), 2331-2341.

[58] O. Mathieu, A. Levacque, E.L. Petersen. Int. J. of Hydrogen Energy 37 (2012), 15393-15405.

[59] Y. Hidaka, H. Takuma, M. Suga. Bull. Chem. Soc. Jpn. 58 (1985), 2911-2916.

[60] M. Kopp, M. Brower, O. Mathieu, E.L. Petersen, F. Güthe . Appl. Phys. B 107 (2012), 529-538.

[61] O. Mathieu, A. Levacque, E.L. Petersen. Proceed. Combust. Instit. 34 (2013), 633-640.

[62] G. Dayma, P. Dagaut, Combust. Sci. Technol. 178 (2006), 1999-2024.

[63] T. Higashihara, K. Saito, I. Murakami. J. Phys. Chem. 87 (1983), 3707-3712.

[64] K. Thielen, P. Roth. Combust. Flame 69 (1987), 141-154.

[65] A. Kéromnès, W.K. Metcalfe, K.A. Heufer, N. Donohoe, A.K. Das, C.-J. Sung, J. Herzler, C.

Naumann, P. Griebel, O. Mathieu, M.C. Krejci, E.L. Petersen, W.J. Pitz, H.J. Curran. Combust. Flame 160 (2013), 995-1011.

[66] D.L. Baulch, C.T. Bowman, C.J. Cobos, R.A. Cox, T. Just, J.A. Kerr, et al. J. Phys. Chem. Ref. Data 34 (2005), 757-1397.

[67] A.A. Konnov. Combustion Flame 156 (2009), 2093-2105.

[68] R. Sivaramakrishnan, K. Brezinsky, G. Dayma, P. Dagaut. Phys. Chem. Chem. Phys. 9 (2007), 4230-4244. 
[69] J. Parks, N.D. Giles, J. Moore, M.C. Lin, J. Phys. Chem. A 102 (1998), 10099-10105.

[70] A.E. Lutz, R.J. Kee, J.A. Miller. Senkin: a fortran program for predicting homogeneous gas phase chemical kinetics with sensitivity analysis. Report SAND87-8248, 1988, Sandia National Laboratories. [71] P. Glarborg, R.J. Kee, J.F. Grcar, J.A. Miller. PSR: a Fortran program for modeling well-stirred reactors. Report SAND86-8209, 1986, Sandia National Laboratories.

[72] P. Ausloos, A. van Tiggelen. Bull. Soc. Chim. Belg. 6 (1951), 433-445.

[73] D.G.R. Andrews, P. Gray. Combust. Flame 8 (1964), 113-126.

[74] V. Zakaznov, L. Kursheva. Zhurnal Prikladnoi Khimii, 53 (1980), 1865-1867. 